Arqueología y Sociedad,

№ 20, 2009

\title{
EXCAVACIONES EN LOS ANDENES DE ANDAMARCA, CUENCA Del Río Negromayo, LuCANAS, AyacuCHO ${ }^{1}$
}

\author{
Mag. Manuel Aguirre-Morales P.2
}

\section{Resumen}

La presente comunicación describe de manera preliminar parte de los resultados de las excavaciones realizadas en el año 2005 en varios sectores de andenes cercanos a la localidad de Andamarca, Distrito de Carmen Salcedo, Provincia de Lucanas, Región Ayacucho. Se describen los andenes investigados y los criterios tomados en cuenta para la elaboración de una tipología de andenes que permite diferenciar los andenes edificados por los Huari de aquellos construidos por los Incas. Con la finalidad de graficar estas diferencias, se presentan algunos ejemplos tomados de nuestras excavaciones y se plantean algunas hipótesis preliminares sobre la construcción, producción y mantenimiento de los andenes. Finalmente, se evalúa la problemática de la investigación arqueológica sobre los andenes discutiendo acerca de su época de construcción inicial, reconstrucciones y la naturaleza de los cultivos en ellos producidos en tiempos prehispánicos, así como los retos que implica su rehabilitación y la producción en andenes hoy abandonados en los Andes centrales.

\section{Palabras Clave}

Andenes, terrazas irrigadas, terrazas de sacano, andenes centrales, Andamarca, Huari, Rucanas, Incas, rehabilitación de bienes.

\begin{abstract}
This communication describes a preliminary part of the results of the excavations conducted in 2005 in several sectors of andenes near the town of Andamarca, District of Carmen Salcedo, Province of Lucanas, in Ayacucho Region. I describe the andenes investigated and the criteria taken into account in the development of a typology of andenes capable of distinguishing the andenes built by the Huari of those built by the Incas. In order to plot these differences, are some examples from our excavations and presents some preliminary hypotheses about the construction, production and maintenance of andenes. Finaly, I analyze the problems of archaeological research on the andenes of their time arguing about the initial construction, rebuilding, and the nature of the crops that they produced in ancient times as well as the challenges of rehabilitation and production andenes today abandoned in the Central Andes.
\end{abstract}

Keywods

Andenes, Irrigated Terraces, Upland Terrace, Central Andes, Andamarca, Huari, Rucanas, Incas, Rehabilitation of andenes.

1 El proyecto de investigaciones arqueológicas fue desarrollado durante los años 2004 y 2005 por la ONGD Cusichaca Trust con la dirección de la Dra. Ann Kendall en colaboración con el autor de la presente comunicación. Sus resultados preliminares han sido presentados en varios eventos académicos. El proyecto fue autorizado por R.D.N. del I.N.C. № 677 - INC - 2005 y su Informe Final fue presentado a dicha institución en marzo del 2006.

2 Profesor de la Escuela Académico Profesional de Arqueología de la Facultad de Ciencias Sociales de la Universidad Nacional Mayor de San Marcos.

Correo electrónico: ayaviri08@yahoo.com 


\section{INTRODUCCIÓN}

La mayor parte de las investigaciones arqueológicas sobre los sistemas de terrazas irrigadas en las laderas de las montañas que denominamos andenes llevadas a cabo en los Andes centrales (Denevan 1987; Burga et al. 1987; Llerena et al. 2004; Mujica E. et al. 2004), han tomado tradicionalmente las narraciones de los cronistas particularmente la versión idealista de Inca Garcilaso de la Vega (1604) - como punto de partida de sus trabajos, bajo la premisa que una alta productividad de los sistemas de terrazas irrigadas fueron la clave de la seguridad alimentaria en los Andes semi-áridos en tiempos prehispánicos (Araujo 1986; Grillo 1990; Earls 1989, 1990; Kendall 1992 b y c, 1994, 2005). A pesar de la importancia de las informaciones coloniales para aproximarnos al contexto socio-político y económico en el cual fueron construidos, manejados y puestos a producir los andenes (Cieza de León 1550; Garcilaso de la Vega 1604; Guamán Poma de Ayala 1607), no se han abordado los problemas principales relacionados con la producción y la productividad en tiempos prehispánicos en dichos sistemas agrícolas ni tampoco se ha hecho un esfuerzo sostenido por investigar la problemática de las prácticas agrícolas y las formas de organización social asociadas al funcionamiento de dichos sistemas de cultivo.

Bonavía y Matos (1990) y Mujica (1995, 2004) han anotado lo que a su juicio son las principales carencias de los estudios hechos hasta el momento sobre los sistemas de terrazas irrigadas: inexistencia de un ordenamiento cronológico de la construcción, uso y distribución de las terrazas en el territorio andino; estimados poco fiables de su cantidad y distribución por regiones; escasos estudios descriptivos desde el punto de vista arqueológico; estudios a nivel local en áreas pequeñas que no son suficientes para generalizar explicaciones o proponer un modelo explicativo para la construcción, producción, manejo y mantenimiento de los andenes para el área andina central en su conjunto.

La literatura arqueológica existente sobre la infraestructura agrícola prehispánica ha priorizado clasificaciones basadas en la ubicación geográfica, en criterios morfológicos, tecnológico-constructivos, cronológicos, corológicos y/o funcionales (Donkin 1979; Mejía 1992; FelipeMorales 1994; Kendall 1984, 2005). A partir de allí, se han propuesto algunas clasificaciones para agrupar los diferentes tipos de terrazas existentes. Por ejemplo, dado que no todas las terrazas han sido construidas para uso agrícola, podemos distinguir cuando menos terrazas para los siguientes usos: producción de cultivos con irrigación ó cultivos de secano; deshidratación en sus plataformas de productos como el ají, la coca o el pescado; evitar la erosión de los suelos; aquellas para uso doméstico con poblaciones en asentamientos; selección y lavado de minerales como la sal u otros. Cada investigador las ha catalogado de acuerdo a las variantes que creyó conveniente priorizar.

Salvo estudios muy puntuales (Masson 1986; Kendall 1992 a y b, 1984, 1994, y 2005; Ramos 1986; Mejía 1992; Treacy 1994) no se ha estudiado la mecánica de los andenes en sus diferentes tipos desde el punto de vista técnico-constructivo y/o agrícola. Por ello, uno de los objetivos del presente proyecto, en el largo plazo, era establecer una tipología morfológico - funcional para establecer una cronología acerca de la construcción de andenes en el valle de Sondondo ${ }^{3}$ y estudiarlos en relación a su producción de acuerdo a su ubicación en diferentes pisos ecológicos.

3 Hemos utilizado intencionalmente las varias denominaciones que el valle tiene en la literatura consultada. Primero, ha sido llamado valle del río Negromayo por J. Ossio (1982). Seguidamente, K. Screiber (1992, 1993, 2005) se refirió a él como valle de sondondo y/ o cuenca del Carhuarazo, Volcán y Apu mayor de la región; nosostros hemos retomado la denominación de Ossio, es decir la de la cuenca del río Negromayo, debido a que esta investigación abarca sólo la parte superior de una de las sub-cuencas del Sondondo o Carhuarazo. 
No se conocen en esta área del valle del río Negromayo, las técnicas originales de distribución del agua en los sistemas de andenes, ni las técnicas constructivas prehispánicas, como es el caso del funcionamiento de los sistemas internos de drenaje identificados al interior de los andenes de Andamarca. Actualmente, se está perdiendo información importante acerca de las antiguas técnicas de funcionamiento, uso y mantenimiento de estos sistemas agrícolas, situación que se grafica cuando, por las deficientes técnicas de riego, los muros de contención de los andenes colapsan y obligan a realizar refacciones anuales de los mismos andenes que se desploman año tras año, tras cada nueva campaña agrícola (Felipe-Morales 1987; 1983).

El propósito de la ONGD Cusichaca Trust (Kendall 1992 a, b y c, 1994, 2005) era llevar a cabo una investigación arqueológica que posibilitara la recuperación de las tecnologías agrícolas prehispánicas -hoy olvidadas o abandonadas por los pobladores actuales- para rehabilitar la infraestructura agraria tradicional y elevar la calidad de vida de las poblaciones rurales del área andina, ampliando la frontera agrícola, elevando y/o diversificando la producción, e integrando esta producción a los mercados regionales o nacionales, todo ello, con la finalidad de garantizar la seguridad alimentaria de las poblaciones rurales andinas (Grillo 1990 a y b; Araujo 1986; Masson 1987; Earls 1989; Kendall 2005; Lumbreras 1996; Aguirre-Morales 2005 a, y b, 2009; Branch et al. 2007).

\section{UBICACIÓN Y CARACTERÍSTICAS GEOGRÁFICAS DEL ÁREA DE ESTUDIO}

Por la gran variabilidad de sus ecosistemas, la zona de alta montaña es privilegiada en cuanto a su diversidad biológica, fundamentalmente en lo que se refiere a plantas alimenticias y medicinales. La disponibilidad de agua es irregular - principalmente en los meses de lluvias de Enero a Marzo- y los suelos agrícolas son escasos, restringidos a superficies donde el suelo es inclinado u ondulado a los que llamamos valles interandinos. La mayoría de los suelos en las partes altas de la Puna, son aptos para el aprovechamiento de pastos y en ellos, actualmente se desarrolla la ganadería de camélidos y ovinos (Dollfus 1981).

El valle interandino del río Negromayo tiene sus nacientes en las lagunas ubicadas entre 4300 a $4600 \mathrm{~m}$ de altitud, en la sierra centro - sur peruana, al norte de la ciudad de Puquio. El recorrido del río Negromayo se inicia con dirección Norte - Sur, su cauce desciende de la Puna girando progresivamente hacia el Este, tomando finalmente dirección Sur - Norte, formando una gran "U". Atraviesa diversos pisos ecológicos (Puna, Suni y Quechua) los cuales se van presentando en forma descendiente, a partir de los bofedales de la Puna hasta llegar el piso del valle que se encuentra a $3300 \mathrm{~m}$, a la altura del pueblo de Andamarca. El río Negromayo finalmente confluye en el río Mayobamba. Geográficamente, los cauces de los ríos Negromayo, Mayobamba y Querobamba van confluyendo progresivamente, drenando la estrecha cuenca del río Sondondo, que termina vertiendo sus aguas en el río Pampas. Todas estas sub-cuencas están modeladas por quebradas pequeñas y grandes, con bajas y altas colinas o lomadas (I.G.N.: Carta Nacional Querobamba (2142) (29 o) (Esc. 1/100,000).

En las partes bajas de zona Quechua, la actividad productiva predominante es la agricultura, practicada mayormente en los andenes irrigados de origen prehispánico, abarcando la zona que va desde el lecho del río hasta puntos ubicados en las laderas a $3600 \mathrm{~m}$ de altitud. En las partes altas de los pisos ecológicos Suni y Puna, la ganadería predomina como actividad económica.

En las áreas de relieve accidentado de los valles interandinos como la del río Negromayo en Ayacucho, es donde los antiguos pobladores 

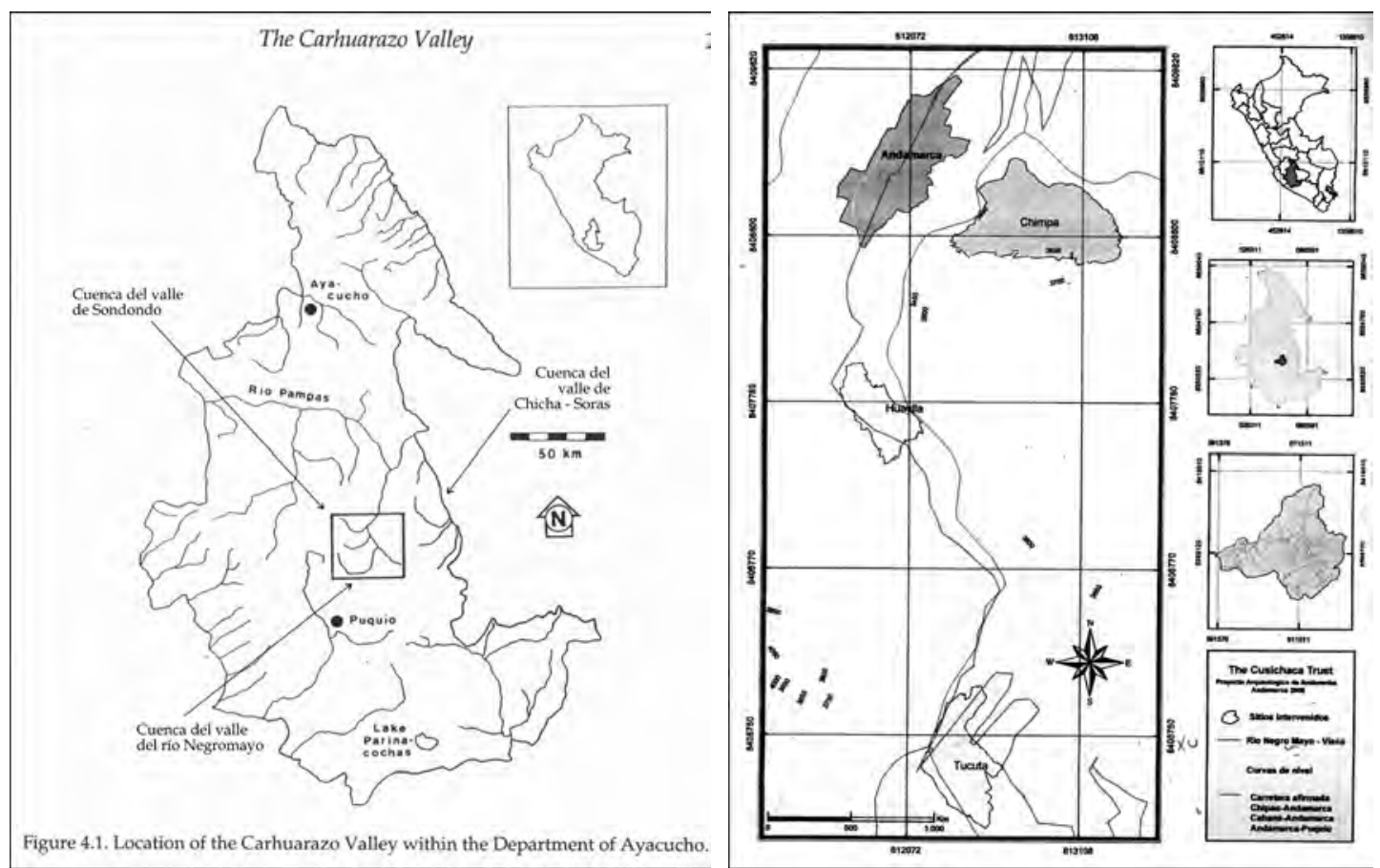

Gráficos 1 y 2. 1) Mapa de ubicación de la cuenca del río Negromayo, y de las cuencas de los río cercanos que han sido investigadas (Tomado de K. Schreiber 1999). 2) Mapa de ubicación de los tres sectores de andenes intervenidos durante nuestras excavaciones en los andenes de Andamarca durante la temporada de trabajo 2005.

construyeron los andenes, sistemas de terrazas irrigados por canales en las laderas de las montañas, utilizados con la finalidad de ampliar la frontera agrícola, evitar la erosión de los suelos y optimizar el uso del agua.

Los andenes estudiados en el presente proyecto, se ubican entre los 2,900 - 3,800 m de altitud, en donde las precipitaciones anuales no exceden los $500 \mathrm{~mm}$. Para la producción agropecuaria, se aprovecharon cuatro zonas de producción mayores (Mayer y Fonseca 1988 a, b y c): las tierras del valle, las laderas de los cerros, las mesetas y la puna alta. El cultivo de secano domina en las zonas altas y el riego es recurrente en las partes bajas de los valles interandinos y en las laderas de sus montañas.

Se trata de una zona relativamente rica, con acceso a nichos de producción diversa, siendo un dato notable la proximidad de una zonas productivas con otras. El cultivo predominan- te es el maíz (Zea mays L.). Además se cultivan la cebada (Hordeum vulgare), la papa (Solanum tuberosum), el olluco (Ullucus tuberosus), la oca (Oxalis tuberosa), las habas (Vicia faba), el trigo (Triticum spp.), la quinua (Chenopodium quinoa), y algunos cultivos para forraje como la alfalfa (Medicago sativa).

La mayor concentración de la población actual se encuentra en zonas intermedias entre los valles y en la meseta altoandina. Los sectores de andenes prospectados y/o excavados en este estudio se ubican alrededor del actual pueblo de Andamarca cuyas coordenadas geográficas son las siguientes: 0612084 - 8409252 (UTM WGS 84 - Zona 18L).

Las familias son propietarias de chacras en pisos ecológicos distintos, tal como sucede en otros parajes de los Andes centrales (Morlon 1992), teniendo por ello la posibilidad de obtener por sí solas variedad de cultivos que se pro- 
ducen en el fondo del valle como el maíz, las habas y diversos cultivos de panllevar y complementarlos con lo obtenido en las zonas de producción ubicadas en los pisos ecológicos Suni y Puna, a través de la producción de tubérculos como la papa, la oca, el olluco y con productos derivados de la crianza de ganado vacuno, ovino y camélidos andinos como la carne en charqui, la lana, el cuero y el guano. La población actual realiza actividades laborales complementarias para poder llevar dinero a sus hogares, empleándose como mano de obra en zonas cocaleras de la ceja de selva, en fundos de producción para la agro-exportación costeños y/o en cualquier otra actividad que no interrumpa ni sea incompatible con los requerimientos de mano de obra que requieren los cultivos o el ganado durante el año (Golte 1980).
III. AnteCedentes de InVESTigACión EN EL VALLE del río Negromayo

Las investigaciones realizadas en la cuenca del Negromayo son escasas y algunas como la presente habían quedado inéditas. Los trabajos de carácter antropológico en la zona de estudio realizados por el antropólogo Juan Ossio (1982), enfocan temas como las formas de la propiedad de la tierra y su vínculo con las relaciones de sociales de parentesco así como la festividad del agua como actividad de mantenimiento de la infraestructura agrícola y ritual de la integración comunal dentro de la comunidad de Carmen Salcedo - Andamarca. Estos últimos pueden ser considerados como el aporte principal que llamara la atención sobre esta región del sur de Ayacucho. J. Ossio (1987) es también uno de los primeros en interesarse y describir la asociación

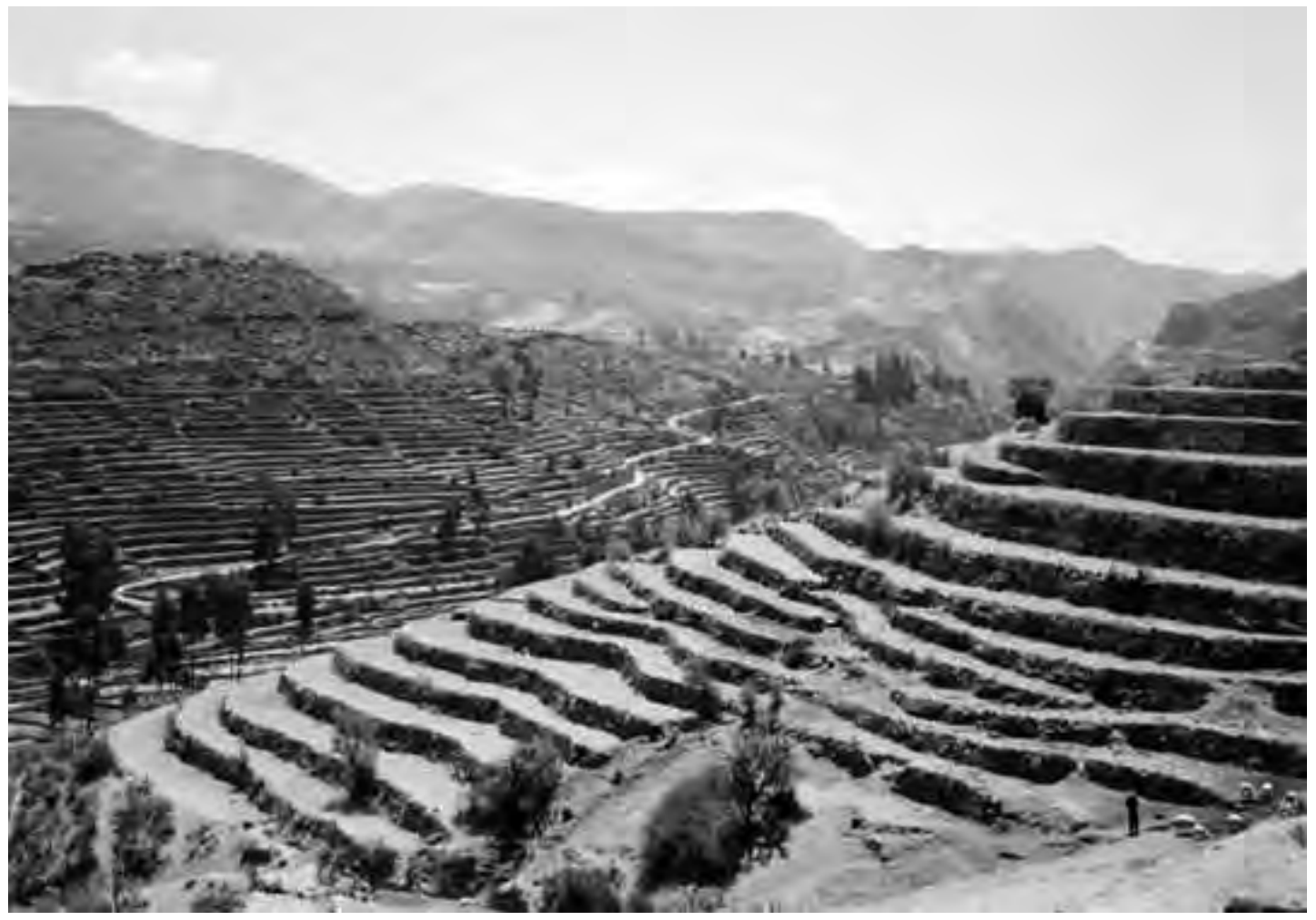

Foto 1. Vista panorámica de los andenes del valle del río Negromayo. A la izquierda, sobre el nivel de los andenes, el sitio arqueológico de Canichi (Como referencia ver artículo de J. Cámara en este mismo volumen). 
existente entre andenes, el riego y el cultivo del maíz en Andamarca en una publicación titulada "Las andenerías de la comunidad de Andamarca (Ayacucho - Perú)".

No obstante, también se han realizado importantes aportes en los estudios arqueológicos para el valle del río Negromayo y para las zonas aledañas. Los más relevantes han sido llevados a cabo por K. Schreiber en el valle del Carhuarazo (Sondondo). Sin embargo, éstos últimos se han centrado en estudiar con mayor detalle las ocupaciones de los períodos Horizonte Medio y Horizonte Tardío, con el objetivo de analizar las distintas estrategias en las formas de ocupación que tuvieron los imperios Huari e Inca en la región, aportando menor cantidad de información para el periodo Intermedio Tardío (Schreiber 1987, 1991a, 1991b, 1993).

La parte superior de la cuenca del Sondondo ha sido estudiada por la propia K. Schreiber (1987) quien enfocó sus investigaciones arqueológicas hacia el establecimiento de una secuencia cronológica cultural particularmente relacionada con la ocupación Huari entre Andamarca y Cabana Sur. La misma autora propone que cambios socio-políticos y económicos estructurales se dieron en esta región con la incursión o conquista del imperio Huari. La vida social de los grupos locales cambió drásticamente pues las modificaciones que introdujeron los Huari transformaron tanto la forma de los asentamientos como también las bases sociales y económicas para la producción agropecuaria. Para el período previo a la conquista Huari (época 1B del Horizonte Medio), estos grupos sociales se asentaban en las zonas más altas, sobre los 4,000 m. de altura, dedicándose mayormente al pastoreo de camélidos y al sembrío de tubérculos en forma extensiva (Schreiber 1987).

Los Huari establecieron sus asentamientos en zonas más bajas. Con la finalidad de incre- mentar la producción agrícola, planificaron e iniciaron proyectos a gran escala para captar fuentes de agua y canalizarlas desde las partes altas de la Puna hacia las laderas artificialmente aterrazadas a través de la construcción de andenes, y, así, aprovecharlas para la producción de cultivos (especialmente el maíz) ampliando la frontera agrícola (Schreiber 1992 y 1993). Introdujeron, además, novedosas técnicas para el mejoramiento de la producción de tubérculos andinos en especial de la papa, así como para la producción de cereales andinos como la quinua y la quihuicha.

De acuerdo a L. Valdéz (2008), los Huari también tuvieron sumo interés en el cultivo del maíz a gran escala para la elaboración de chicha, la bebida ritual por excelencia en los Andes centrales.

Estos cambios en las técnicas de la producción agrícola se mantuvieron con los grupos sociales locales asentados posteriormente en la zona después de la caída de la hegemonía Huari. Añadidamente, casi todos los asentamientos edificados durante esa época fueron abandonados. Schreiber (1993), ha establecido una secuencia cronológica para la región en base a una recolección de cerámica de superficie. La fase que abarca el momento de declive Huari es la denominada Marke, que es la única que ha sido identificada a partir de su ubicación en las secuencias estratigráficas en sus excavaciones del centro administrativo Huari de Jincamocco (Schreiber 1991b).

Esta prospección regional que realizó en 1981, le permitió también plantear la secuencia para las fases tardías, identificando la presencia de 30 alfares y definiendo 13 estilos agrupados en tres fases denominadas Marke (Horizonte Medio 3 y 4); Toqsa (Intermedio Tardío) y Jasapata (Intermedio Tardío e Inca) (Schreiber 1993) ${ }^{4}$.

4 Para mayor detalle sobre los temas relativos a la secuencia cerámica remitirse a la comunicación de S. Berrocal en este mismo volumen. 
Con relación a la ocupación Inka en la zona del Carhuarazo, propone que durante la fase Jasapata, se produjo la incursión Inca a la zona de Andamarca, tomando así el control total de valle. Sin embargo, esto ocurrió sin que ocurrieran cambios drásticos en el patrón de asentamiento local, con la excepción de la edificación de centros de carácter administrativo, colcas para el almacenaje de la producción, tambos, y el refuerzo de la red de caminos y puentes (Schreiber 1993).

Los estudios arqueológicos ejecutados por Frank Meddens durante los 80, complementaron los estudios palinológicos realizados analizando las muestras de sedimentos extraídos de tres lagunas locales de la cuenca del Chicha Soras, estudios que fueron ejcutados por el Royal Holloway College de la Universidad de Londres. Estos produjeron interesantes resultados publicados de una serie de artículos sobre los estudios de paleo-suelos y paleoclima para la zona donde se ubican los andenes de este valle y las regiones aledañas (Meddens 1981 y 1984). Las primeras dos campañas arqueológicas realizadas entre 1999 y 2001, durante las cuales se llevaron a cabo estudios en la cuenca superior del Chicha Soras, abarcaron ambas márgenes la cuenca mencionada. Por la margen izquierda, en el distrito de Larcay, Provincia de Sucre, Ayacucho, y en la margen derecha en el distrito de Pampachiri, Provincia de Andahuaylas, Apurímac. Estos trabajos dieron lugar a la primera etapa de investigación arqueológica que consistió en definir la función de algunos andenes y canales expuestos, el estudio de su construcción interna y su período de construcción. Las excavaciones se realizaron con la finalidad de recuperar información medio ambiental a través de los estudios de los suelos estratificados dentro de los andenes. Se logró encontrar suelos enterrados (paleo- suelos) siendo los resultados de estos estudios paleoambientales la base que apoya la hipótesis de la reconstrucción de andenes Huari por sociedades más tardías como los Incas (Meddens 1990 y 1991; H.M. Keeley y F. Meddens 1993).

La ONGD Cusichaca Trust, dirigida por A. Kendall, también ha realizado, desde el año 2003, la documentación y mapeo de los sitios arqueológicos para un proyecto de apoyo y documentación para las comunidades de la zona que desean desarrollar circuitos turísticos que abarcarán las cuencas del Negromayo y del Chicha Soras. Además, ha realizado la evaluación del potencial turístico arqueológico y analizado la posibilidad de la rehabilitación de los canales y andenes prehispánicos para elevar su potencial de rendimiento productivo, infraestructura que sigue parcialmente abandonada por los comuneros del distrito en el presente. Finalmente, durante el año 2006, Cusichaca Trust, también se llevó a cabo un inventario general de andenes en el valle de Chicha Soras que quedó limitado a la margen derecha a los distritos de Pampachiri y Pomacocha 5 .

\section{Presentación de los trabajos realizados EN ANDAMARCA}

Los andenes se ubican la mayor parte de las laderas de los cerros que ocupan las terrazas fluviales adyacentes al cauce del río Negromayo ubicadas a $3150 \mathrm{~m}$ (Andamarca) hasta los 3750 m, razón por la cual se buscaba obtener un muestreo amplio que sea representativa de los diferentes pisos ecológicos existentes en la región para obtener información sobre los tipos de andenes existentes a diferentes altitudes. Los andenes registrados y excavados en el valle del río Negromayo, se concentran en tres sectores: Chimpa, Huaylla y Tucuta.

$5 \mathrm{El}$ autor fue el Jefe de campo de aquel proyecto de inventario de andenes en la cuenca del Chicha Soras. Paralelamente, consultores de la U.N.A.L.M. contratados por la misma ONGD Cusichaca Trust para elaborar un inventario paralelo con la metodología del INRENA, completó el recorrido e inventario de los ocho (08) distritos de la parte alta de la cuenca del Chicha Soras. Sin embargo, desconocemos sus resultados y si estos han sido publicados. 


\section{Hipótesis DE TRABAJO}

La hipótesis básica del trabajo, siguiendo los postulados de K. Schreiber (1987) y Meddens $(1990,1991)$ era que en el valle del río $\mathrm{Ne}$ gromayo (Sondondo), la expansión del cultivo del maíz, en base a la construcción de andenes irrigados, fue impuesta por los Huari en la época 2 del Horizonte Medio. Siguiendo esta propuesta, e intentando llenar vacíos en el conocimiento arqueológico acerca de la filiación cronológica de la infraestructura agrícola de la región, mi planteamiento principal es que sólo bajo el gobierno de una entidad estatal con poder centralizado de carácter imperial, es posible someter a poblaciones a través de la violencia armada o fuerza militar y/o bajo la coerción de una ideología religiosa muy sólida. Con ello, se puede concebir la posibilidad de construir sistemas de andenes a gran escala, debido a que estos últimos trabajos presuponen la organización y el traslado de ejércitos de trabajadores de un valle a otro, $y$, la posibilidad de tener sistemas de almacenaje capaces de contener productos para el mantenimiento de dicha masa crítica de trabajadores para realizar obras previamente planificadas mientras éstas duren, las cuáles exigen a su vez, exigen enormes e incalculables movimientos de suelos, piedras y materias diversas con la finalidad de lograr que todas las laderas de una cuenca o sub-cuenca sean aptas para la agricultura. Estos sistemas de andenes, construidos en ambas márgenes de los ríos de la región estudiada, requieren contar con especialistas en hidráulica y agronomía que sepan manejar y adaptar las técnicas agronómicas a cada piso ecológico, cada uno de ellos con características geomorfológicas propias de determinados parajes, los cuales poseen vocación agroecológica y productiva muchas veces diferente de un subsector a otro, habiendo sido necesario el control de factores de producción como son el agua, el suelo y el clima, éste último, basados en la posibilidad de predecir, a través de sofisticados calendarios agrícolas, los irregulares ciclos climáticos andinos, para una óptima producción agrícola.

Con ello, respaldo la hipótesis planteada por Treacy (1984) en el sentido de que las terrazas de secano preceden en el tiempo a los andenes o terrazas irrigadas, y, que así como los Huari construyeron dichos sistemas de andenes, los Incas modificaron la estructura interna de los andenes pre-existentes, reconstruyéndolos para darles vocación productiva maicera, ampliando así la superficie agrícola destinada a este cultivo como producto prioritario para los intercambios con las élites locales y como elemento ritual básico en la ideología imperial (Hastorf 1990; Hastorf y Johannessen 1993). Esta hipótesis no contradice lo sugerido por Valdéz (2008), en el sentido que los Huari ya hubiesen tenido un interés particular por el maíz para fines semejantes. Esta ampliación de la frontera agrícola para el maíz en tiempos de los Incas sobrepasó los $3,800 \mathrm{~m}$. de altitud debido a los favorables cambios climáticos ocurridos desde el Intermedio Tardío.

\section{LA TIPOlOGía DE ANDENES PROPUESTA POR A. KENDALL (2005) ${ }^{6}$}

Los trabajos previos realizados por Cusichaca Trust en Cusco y Apurímac, (Kendall 1976, 1984, 1992, 1994) y las prospecciones llevadas a cabo en Andamarca, conjuntamente con el autor de esta comunicación, durante el año 2004, permitieron a la Dra. Ann Kendall (2005), plantear una tipología preliminar de andenes que nos sirvió de base para llevar a cabo una clasificación de aquellos registrados durante la primera fase de reconociendo en el trabajo de campo durante el año 2005.

6 En esta publicación preparada para la Revista del Museo de Arqueología de San Marcos no se tomó en cuenta el libro de A. Kendall (2009) presentado y a disposición del público después de la entrega de este artículo a los editores, razón por la cual la tipología presentada se basa en la comunicación personal establecida con la mencionada autora y en los trabajos realizados en conjunto como parte de las excavaciones en Andamarca en 2005. 


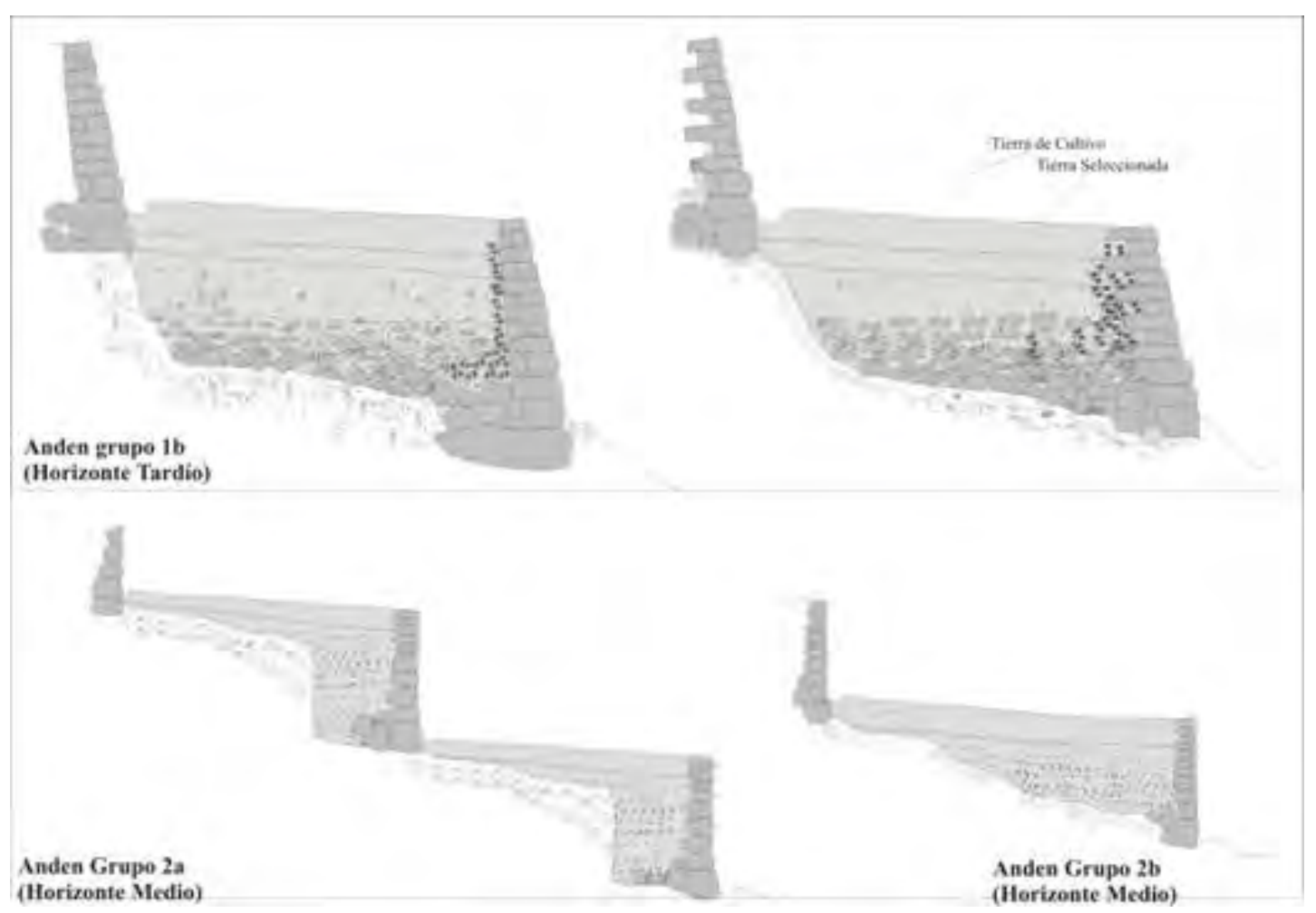

Gráfico 3. Representación de los tipos de andenes 1a, 1b, $2 a$ y 2 b, según A. Kendall (2005) para el Horizonte Medio y el Horizonte Tardío (Kendall: comunicación personal 2004, 2005, 2006).

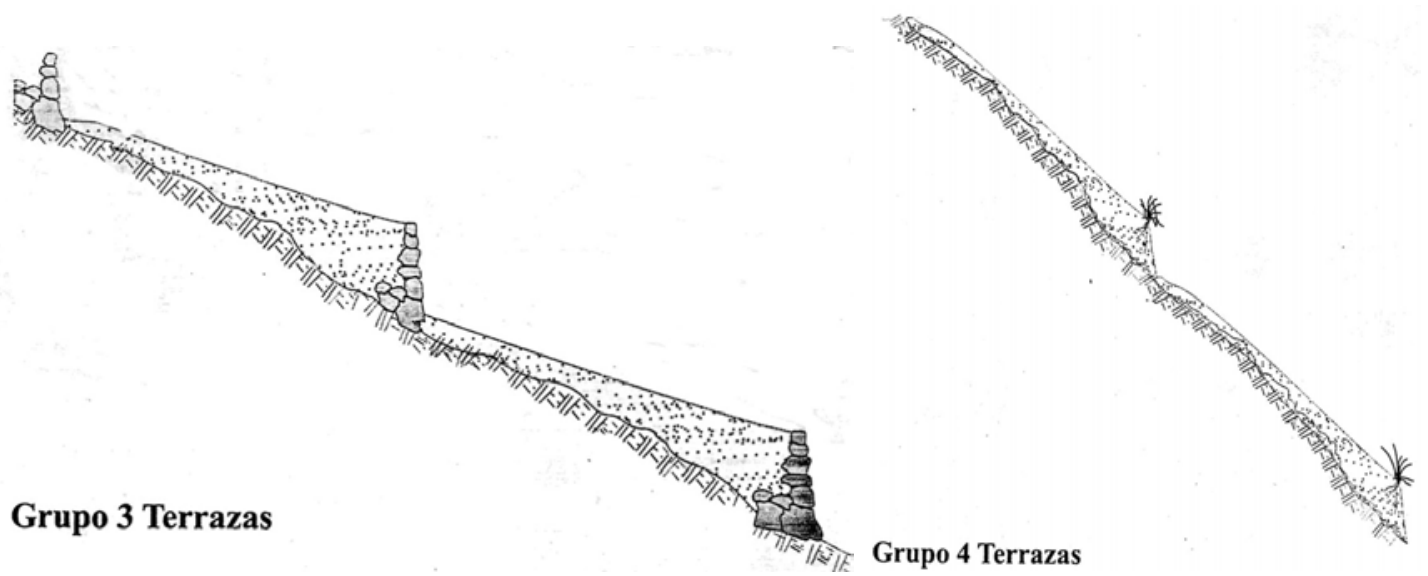

Gráfico 4. Representación de los tipos de terrazas 3 y 4 según la tipología propuesta por A. Kendall (2005) (Kendall: comunicación personal 2004, 2005, 2006). De acuerdo a la autora mencionada podrían haberse construido en el Intermedio Temprano (Tipo 3). Treacy (1984), quien propuso la hipótesis por primera vez, planteaba que los andenes irrigados reemplazaron a las terrazas de secano. Los terrenos de labranza y cultivo en ladera son los mayoritarios y más simples. Las comunidades alto-andinas, los utilizan con rotación de cultivos y barbecho sectorial en terrenos comunales con trabajo comunitario. 
Cuadro 1. Características de los andenes en la tipología propuesta por A. Kendall ${ }^{7}$

\begin{tabular}{|l|c|c|c|c|}
\hline TIPO & $\begin{array}{c}\text { Perfil de la } \\
\text { plataforma }\end{array}$ & $\begin{array}{c}\text { Muro de } \\
\text { contención }\end{array}$ & Riego & $\begin{array}{c}\text { Factores } \\
\text { distintivos }\end{array}$ \\
\hline 1. Andén & Casi horizontal & $\begin{array}{c}\text { Inclinado hacia } \\
\text { el interior }\end{array}$ & $\begin{array}{c}\text { Generalmente } \\
\text { con irrigación }\end{array}$ & $\begin{array}{c}\text { Estratos interiores con } \\
\text { capas de suelos diferen- } \\
\text { ciadas. Cascajo detrás del } \\
\text { muro de contención. }\end{array}$ \\
\hline 2. Andén & Casi horizontal & Vertical & $\begin{array}{c}\text { Con y sin canales } \\
\text { de irrigación. } \\
\text { Actualmente } \\
\text { muchas son te- } \\
\text { rrazas de secano. }\end{array}$ & $\begin{array}{c}\text { Relleno de algunas pie- } \\
\text { dras detrás de la cimen- } \\
\text { tación. Estratos interiores } \\
\text { con capas de suelos } \\
\text { diferenciadas. }\end{array}$ \\
\hline Andén & Inclinado & $\begin{array}{c}\text { Rústico con un } \\
\text { muro de conten- } \\
\text { ción de dos o tres } \\
\text { hileras de piedra }\end{array}$ & $\begin{array}{c}\text { Sin irrigación } \\
\text { Mayormente te- } \\
\text { rrazas de secano. }\end{array}$ & $\begin{array}{c}\text { Pocas piedras en los relle- } \\
\text { nos de las capas internas } \\
\text { de suelos. }\end{array}$ \\
\hline 4. Terraza de \\
labranza & $\begin{array}{c}\text { En pendiente } \\
\text { pronunciada }\end{array}$ & $\begin{array}{c}\text { Algunas piedras } \\
\text { o vegetación re- } \\
\text { tienen los suelos }\end{array}$ & Sin irrigación & $\begin{array}{c}\text { Formada por erosión y } \\
\text { apisonamiento en alto } \\
\text { declive }\end{array}$ \\
\hline
\end{tabular}

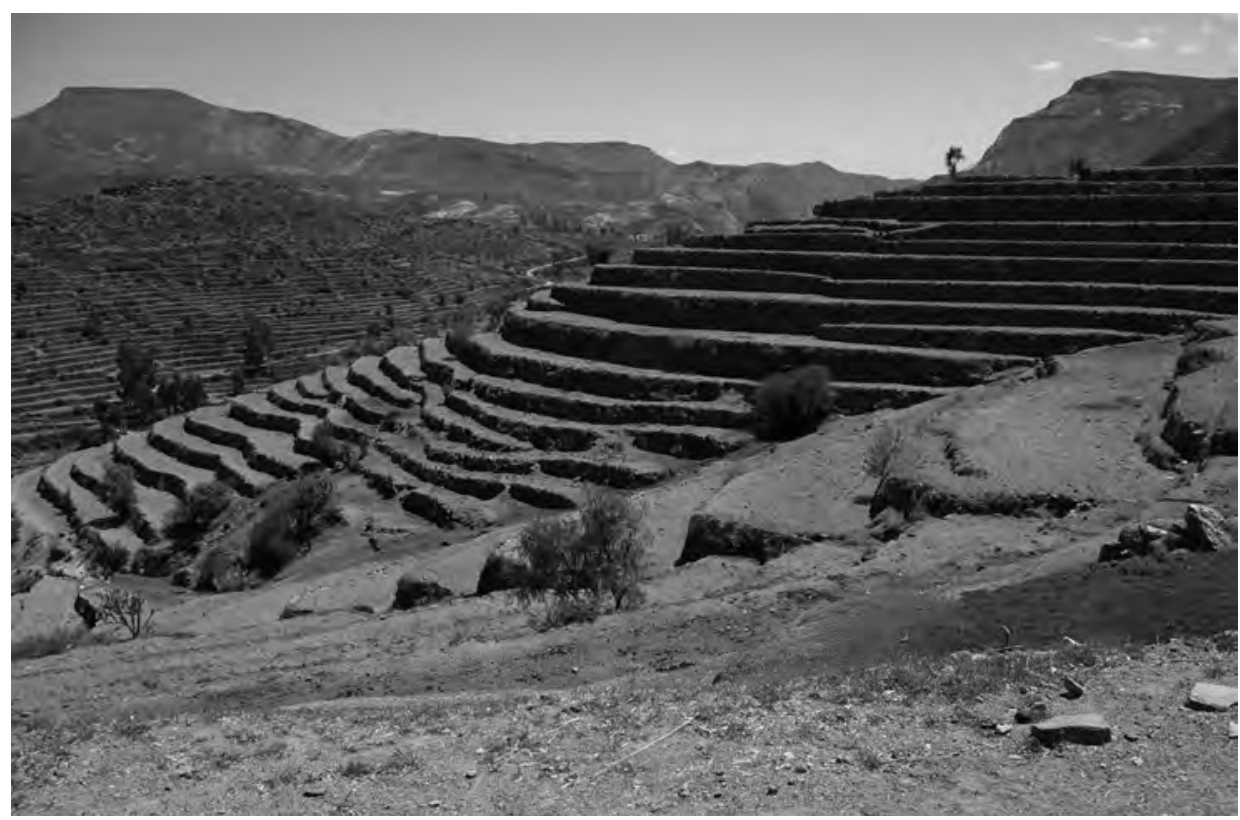

Foto 2. Tipo $1 a$ y 1b.- Andenes Incas tipificados por su forma constructiva: Sección del muro trapezoidal realizado en dos hileras, inclinación hacia el interior entre 5 y $20^{\circ}$, esquinas con amarres y presencia de cascajo en el andén adosado a la cara interna del muro cuya función es el drenaje. Andenes ubicados en el sub-sector de Patahuasi, Sector de Chimpa en Andamarca.

7 Algunos datos complementarios han sido introducidos por el autor en el texto del cuadro, sin alterar la propuesta básica de la tipología de A. Kendall (2005). 


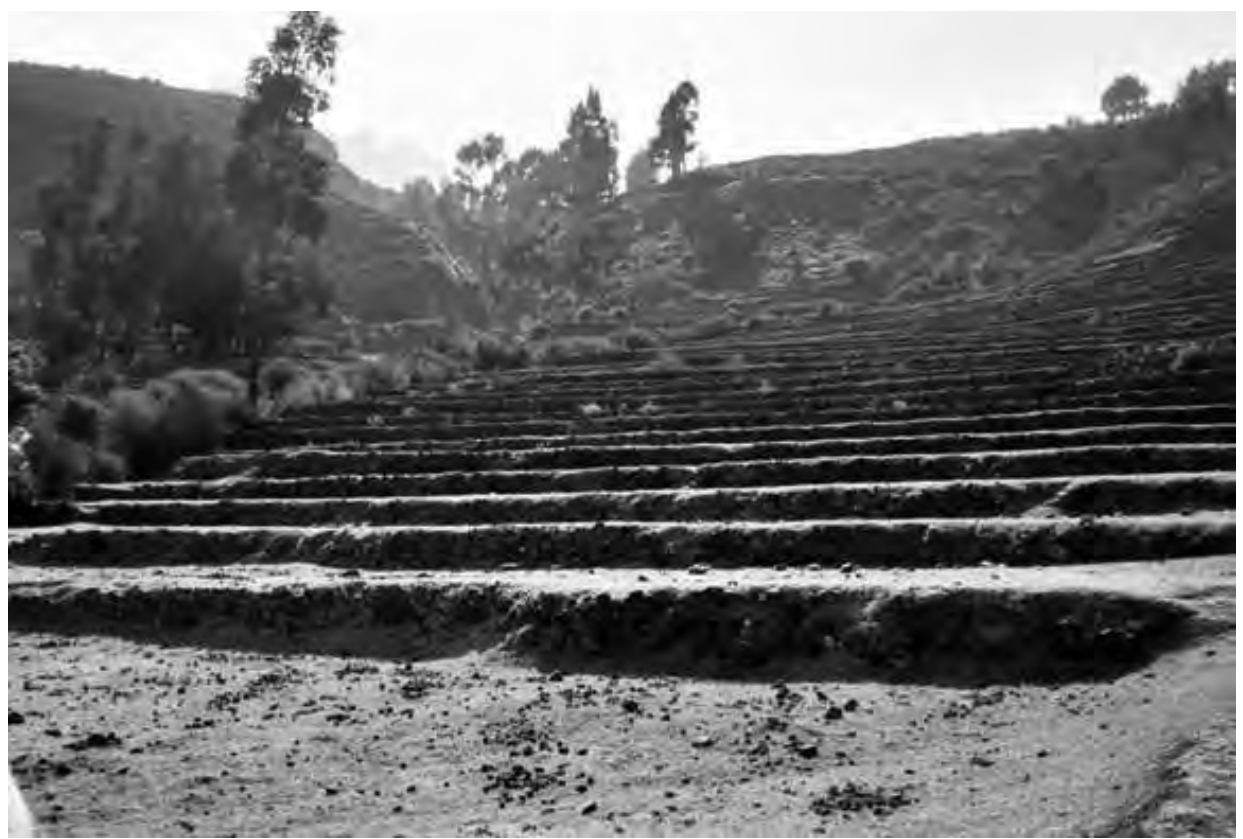

Foto 3. Tipo $2 a$ y 2b.- Andenes pre-incas de filiación Huari (Horizonte Medio). Se caracterizan por muros construidos a una sola hilera, sin amarres en las esquinas, y muros de contención verticales. Los andenes suelen ser más bajos y las plataformas más anchas.

\section{FINES Y OBJETIVOS DE LA CAMPAÑA DE 2005}

Los objetivos del proyecto arqueológico en Andamarca para el año 2005 fueron los siguientes:

a) Estudiar la tecnología constructiva de los andenes para poder diferenciarlos cronológicamente y establecer una tipología de andenes para el valle del río Negromayo.

b) Realizar un estudio comparativo de los andenes de Andamarca con relación a los andenes de Chicha Soras y de aquellos estudiados por la Dra. A. Kendall en el Cusco.

c) Documentar etnográficamente, a través de entrevistas a los comuneros, acerca de las acciones de mantenimiento y cambios que pueden haber ocurrido y que queden en la memoria de los propietarios de los andenes.

\section{Metodología del trabajo de CAMPo}

Los métodos y procedimientos seguidos en los trabajos de prospección y excavación han priorizado las técnicas más adecuadas para cada fase de la investigación, las misma que nos ayudaron a recuperar la mayor información posible sobre los andenes. Debido a la complejidad de las capas internas de los andenes y a la gran variedad de los elementos arquitectónicos identificados en ellos, también tuvimos que reformular las fichas de registro para las prospecciones y así mismo modificar las fichas de registro para las excavaciones a realizarse ${ }^{8}$.

\section{Etapas del trabajo de campo}

La metodología de trabajo para la investigación en andenes se dividió en tres etapas sucesivas:

8 La presentación de la metodología para realizar prospecciones, mapeos e inventarios de andenes (que consideramos útil para los estudios de sistemas de andenes desde el nivel de estudio de una cuenca hasta el estudio de un único andén) y la descripción detallada de la metodología para realizar excavaciones en andenes serán motivo de una próxima publicación donde presentaremos en detalle el procedimiento metodológico desarrollado en el inventario de andenes del Valle del río Chicha-Soras en el año 2006 y en la excavación de Andamarca del 2005. 
1.- Reconocimiento general y evaluaciones; 2.Prospección sistemática y calas prospectivas, y, 3.- Excavaciones en trincheras en los andenes previamente seleccionados.

\section{Trabajos realizados en la Temporada 2005}

Los sectores de andenes estudiados o intervenidos se ubican en las zonas ecológicas Quechua y Suni, a ambas márgenes del río Negromayo, en los alrededores de la actual población de Andamarca, en el distrito de Carmen Salcedo.

\section{El sector de andenes de Chimpa}

El sector de andenes de Chimpa (que quiere decir "al frente") se ubica en la margen derecha del río Negromayo en el cerro Uchuypata y al frente del sitio arqueológico del poblado de Canichi, asociado al periodo Intermedio Tardío en Andamarca. Se trata de uno de los sectores mejor conservados de andenes en la cuenca y sus 39.5 ha se ubican en toda la ladera de la margen derecha del valle desde la primera terraza fluvial del río hasta los $3800 \mathrm{~m}$ de altura. El canal principal que abastece de agua este sector se denomina canal de Orcco y tiene una extensión de $18 \mathrm{~km}$. En la parte baja, cercana al cauce del río, se ubican zonas de potreros y corrales de animales, mientras que conforme se asciende por los pisos ecológicos de Quechua y Suni, los andenes recubren totalmente la ladera. El sector de Chimpa está a su vez sub-dividido en varios sub-sectores, de vocación productiva diferente, entre los que podemos mencionar: Chanchachi, Sillitu, Patahuasi, Loccacni, Ccaccatuna, ente otros. El maíz, en sus variedades, es el cultivo predominante hasta el día de hoy. Los andenes de la parte baja y de las partes al-

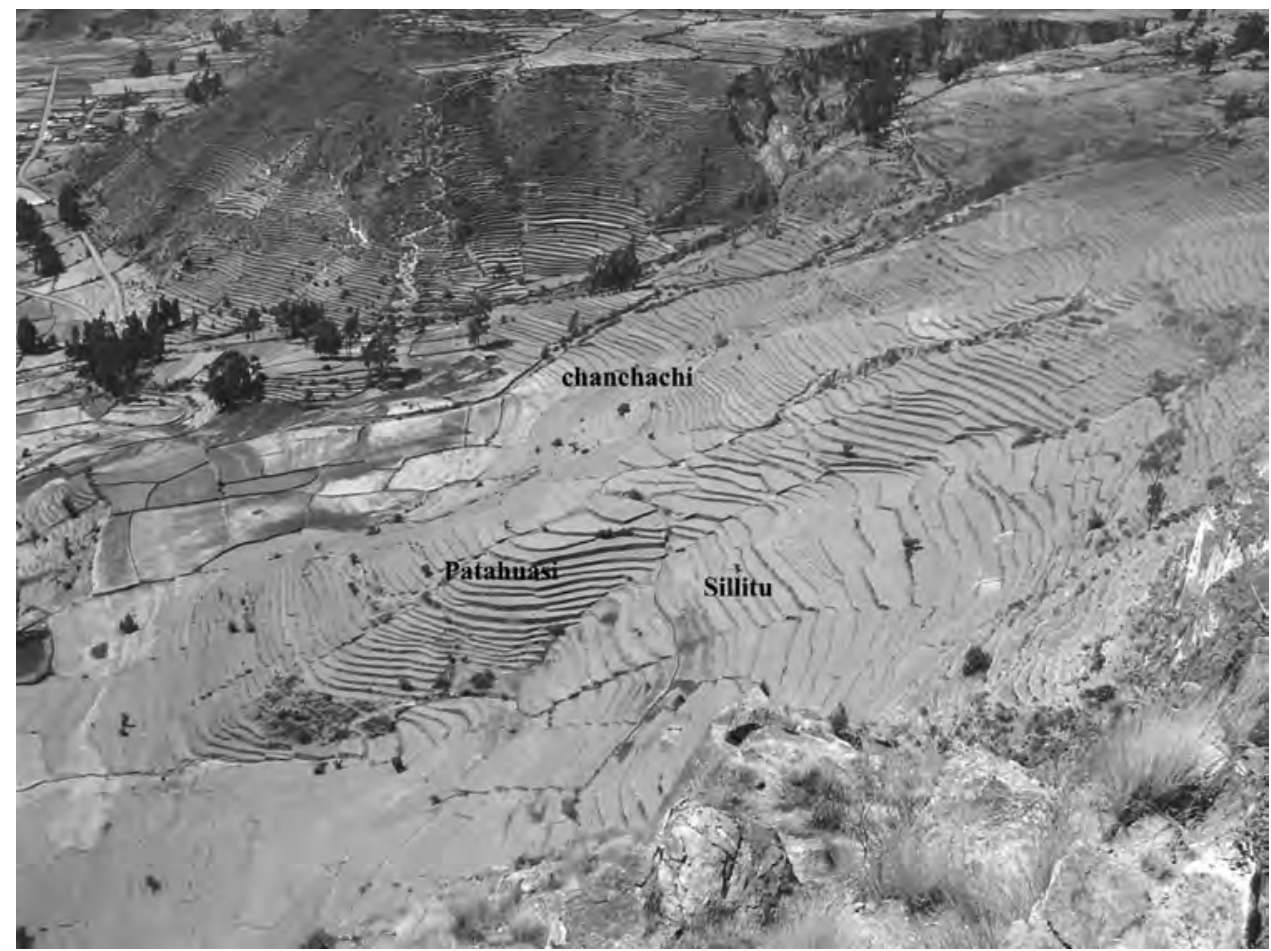

Foto 4. Vista panorámica del sector de andenes de Chimpa y ubicación de los sub-sectores intervenidos durante el proyecto. 
tas poseen muros mejor conservados. La parte intermedia de la ladera en Chimpa presenta muros reconstruidos en numerosas zonas. Otros sectores se hayan destruidos parcialmente por el abandono de sus dueños, inadecuadas técnicas de riego y/o por la introducción de ganado que circula libremente después de las cosechas para pastar, lo que produce el desplome de los muros de contención de los andenes (Felipe-Morales 1983, 1987 y 1994; Aguirre-Morales 2005). Los andenes de Chimpa presentan mayor cantidad de piedras traídas del río (cantos rodados) de tamaño regular con las caras planas colocadas en la parte frontal de los andenes. Muchos andenes poseen claramente una, dos o tres hileras en la parte de la base del muro que forman una primera etapa constructiva. En estos casos, la(s) primera(s) hilera(s) están más adelantadas (10 a 20 centímetros) que la segunda etapa de construcción, la cual está conformada muchas veces por piedras de mayor tamaño, canteadas, regularmente dispuestas, y, con la cara más plana dispuesta hacia la parte frontal del andén. A partir de esta segunda sección o nivel, el muro del andén comienza a tener una inclinación hacia el interior, la cual varía en grados según sea el caso. Es posible que las primeras hileras verticales formen parte de andenes más tempranos que fueron reconstruidos después de una etapa de abandono o remodelados por otros agricultores en una etapa posterior (por ejemplo, andenes Huari remodelados por los Incas).

\section{El sub-sector de andenes de Chanchachi}

\section{- Sector de Chimpa}

Durante los trabajos de reconocimiento realizados previamente, se había identificado andenes de probable filiación Huari de acuerdo a la tipología elaborada por A. Kendall. Muros de contención verticales con una elevación promedio de $1 \mathrm{~m}$ de altura y plataformas de mayor amplitud de ancho homogéneo en ese sub-sector fueron considerados como indicadores de su época de construcción.
Evaluación 03 en el sub-sector de Chanchachi - Sector de Chimpa

Inicialmente, se escogió el andén № 09 para llevar a cabo la evaluación 03. La ubicación exacta de los andenes intervenidos es: UTM: (WGS 84) 18L 0612649 - 8409132, a una altitud de 3,423 m. La caída de los muros laterales de tres andenes consecutivos dejó expuesto el perfil en sección de los mismos. El perfil expuesto brindó la siguiente información: para la construcción del andén, el suelo natural fue excavado a manera de gradas. De abajo hacia arriba, los primeros rellenos combinan cascajo, grava y suelo natural, mientras que la capa de relleno de mayor grosor del andén está constituida por suelo arcilloso-limoso. La capa superficial de cultivo es más bien areno - limosa. Quedan en evidencia constantes fenómenos erosivos que dieron lugar a la reconstrucción en varios momentos de estos andenes. En resumen, en el perfil se pueden leer hasta tres etapas de reconstrucción, la última de ellas de muy mala factura que debe ser bastante reciente. Con todo ello, también se comprobó que se construyeron andenes en las partes bajas cercanas al río en tiempos prehispánicos.

Excavación de la cala 03 en el sub-sector de Chanchachi - Sector de Chimpa

La excavación de la cala 03 ubicada en subsector de Chanchachi - Sector de Chimpa, se ubica en el andén № 11 a una altitud de 3,483 m. Su localización exacta es: UTM (WGS 84): 18L 0613008 - 8409097. Se excavó en el andén № 11 de Chanchachi para poder documentar la constitución interna del mismo, es decir, las capas interiores que lo componen. Se requería conocer la composición interna de las capas del andén con la finalidad de tener una primera aproximación al estudio de los suelos agrícolas y de las capas de relleno de los andenes. Para ello, se procedió a excavar una cala de $1 \mathrm{~m}$. x $1 \mathrm{~m}$. en la parte de la plataforma del andén cercana a 


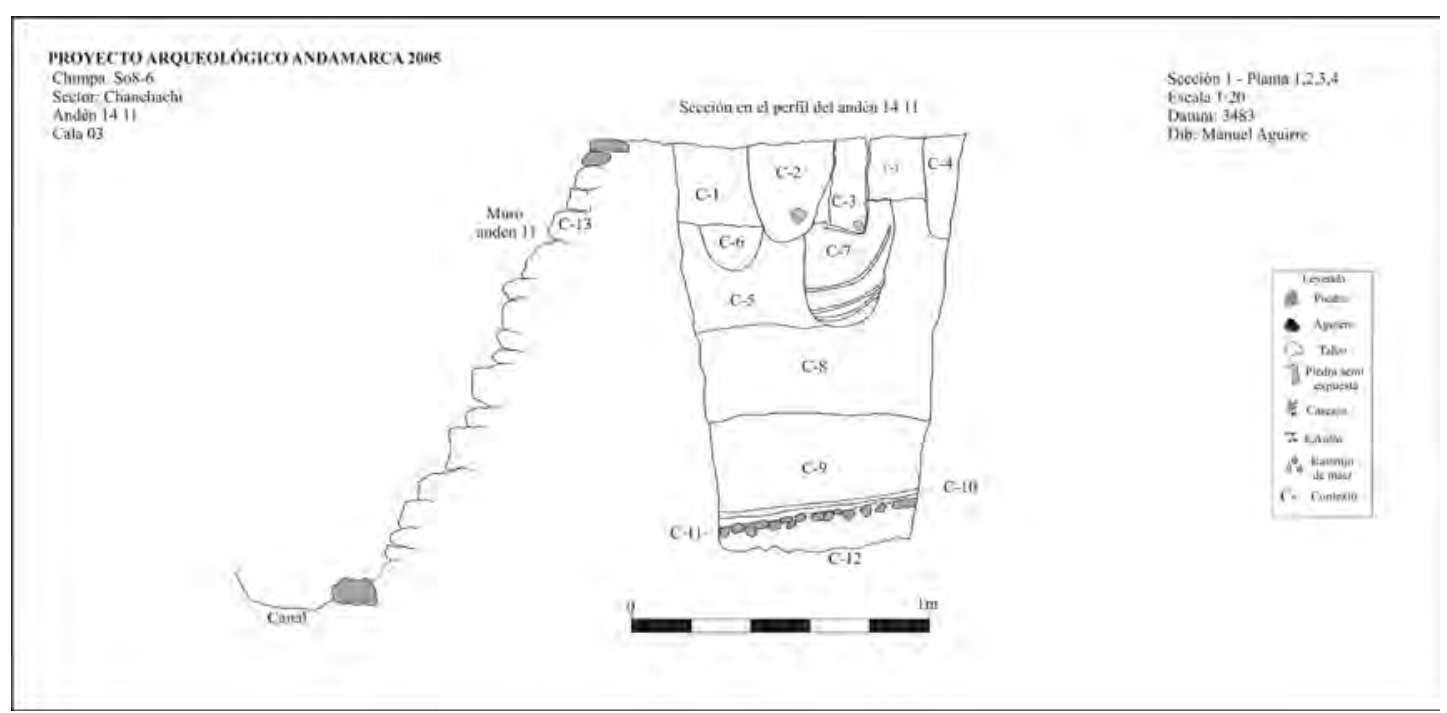

Grafico 5. Dibujo del perfil N de la cala 03 excavada en el andén № 11 en el sub-sector de Chanchachi - Sector de andenes de Chimpa.

PROYECTOARQUEOĹLGico ANOAMARCA Zoos Chenew Sos-M
Secive Panbias Aadenes 14 y 15

Cataำi:
Piats 1.23 -cens 1

Eacala 1/20

Datum 3 dinn

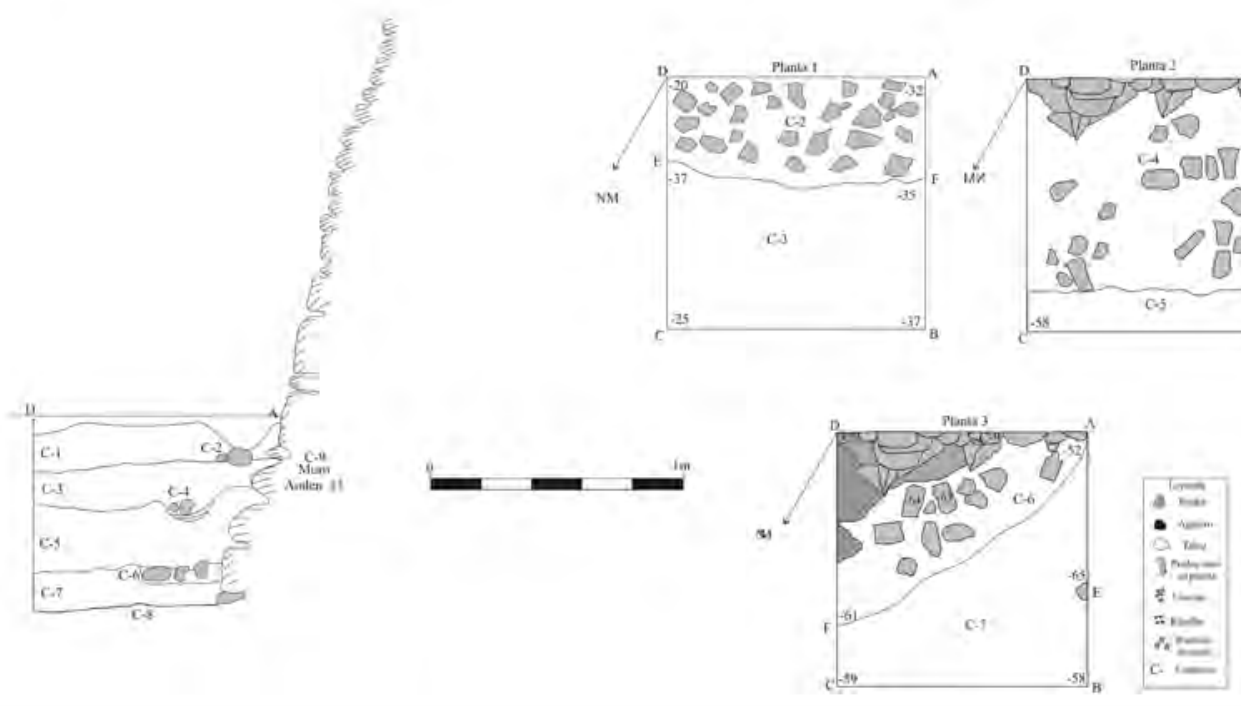

Gráfico 6. Dibujo del perfil Norte de la cala 01 excavada en el andén 14 hacia la base del muro de contención del andén 15 en el que se observan diferentes niveles de suelos agrícolas y su relación con las reconstrucciones realizadas en el muro de contención del andén 15. También contiene dibujos de planta de esos niveles de suelos. Nótese en el dibujo de Planta 3 que la orientación de los cimientos del muro de contención más antiguo tiene otra orientación que los construidos posteriormente. 
la cabecera del muro de contención del andén № 11 .

La excavación de la cala 03 reveló la existencia de una serie de canales de riego o pequeñas acequias en las dos capas más superficiales de la plataforma del andén. Algunos presentan incluso varios niveles de uso detectados en el perfil de la cala por la presencia de cauces de arcilla muy fina sobrepuestos al interior de uno de los canales (ver gráfico 3). Se documentaron 07 capas principales. De arriba abajo, las dos primeras representan suelos agrícolas seleccionados. La tercera y la cuarta son rellenos para la construcción de la plataforma del andén mientras que una delgada capa de arcilla y una capa de cascajo, ambas subyacentes a aquellas, permiten el adecuado drenaje del agua hacia el andén inferior.

\section{El sub sector de andenes de Patahuasi en Chimpa.}

El sub-sector de Patahuasi se encuentra en la parte central del sector de andenes de Chimpa donde se ubican los andenes más afectados por la erosión y el mal manejo del reigo al haberse perdido las bocatomas del canal secundario que lo irriga. Esto tiene como consecuencia que los campesinos utilicen prácticas de riego inadecuadas, las que, al primer descuido, ocasionan grandes daños a los muros de contención de los andenes que se desploman con facilidad. Es también la zona que ha sufrido mayores remodelaciones desde la època Inca, donde sería oportuno retomar excavaciones para ver si debajo de los actuales andenes no subyacen estructuras de carácter doméstico como en Huaylla (ver Infra).

La Cala 01 de $1 \mathrm{~m}$ x $1 \mathrm{~m}$, excavada en los andenes en el sub-sector de Patahuasi - Sector de Chimpa se ubica en el andén № 15 a una altitud de 3,406 m.. Su localización exacta es: UTM (WGS 84): 18L 0612948 - 8409075.

Se decidió trabajar la cala 01 en el andén 15 para poder documentar con este ejemplo cómo estaban construidas las bases de los andenes que es la parte más antigua en la construcción del andén. La parte inferior del muro del andén 15 presentaba evidencias de una sólida construcción sin remodelaciones modernas. La cala realizada sobre la canaleta de riego y parte de la plataforma de cultivo del andén 14, adosados al muro en la actual plataforma del andén № 15 , estuvo destinada a evaluar la base del muro de ese andén № 15 .

Durante la excavación del andén № 14 realizada hacia la base del andén № 15 , se llegó a documentar cuatro eventos de caída y reconstrucción del muro: desde la superficie de la plataforma del andén № 14 hacia arriba, el muro del andén № 15 sufrió dos remodelaciones. una primera, en tiempos de los Incas (revelada por la inclinación del muro) y una última, en tiempos modernos. Al excavar sin embargo, pudimos notar que otras dos remodelaciones adicionales estaban asociadas a los cimientos del muro del andén № 15. El muro original parece haber tenido una orientación de $30^{\circ} \mathrm{NE}$, totalmente diferente que la que le dieron posteriormente de $65^{\circ} \mathrm{NE}$. Incluso las piedras que cayeron del mismo muro se presentan alineadas con la misma orientación. Se constata que para asentar las bases compuestas por grandes piedras canteadas se excavaron cimientos y se colocaron cuñas para darle estabilidad al muro. En un segundo evento constructivo, se trabajó principalmente con cantos rodados grandes trasladados desde el cauce del río cambiando la orientación del muro de contención del andén № 15. Las dos caídas posteriores de piedras del muro de contención registradas están más bien alineadas con la nueva orientación del mismo.

\section{El sub-sector de andenes de Sillitu - Sector de Chimpa}

El sub-sector de andenes de Sillitu (nombre que proviene de la alusión a la piedra de sillar abundante en el roquedal del farallón que lo limita 
al Este), se encuentra ubicado en la parte Sur del Sector de Andenes de Chimpa. Representan lo que Treacy (1994) llamaría andenes de "contorno" ya que los muros de contención no son lineales sino más sinuosos, adaptándose a la topografía natural siguiendo las curvas de nivel. La mayor parte de estos andenes fueron previamente identificados como de filiación Inca debido a la inclinación de sus muros y al cascajo que presentaban detrás de la cara interna del muro de contención, cuestión que se hizo explícita durante las evaluaciones realizadas en la primera etapa de trabajo. Los andenes de Sillitu han sufrido numerosas remodelaciones a lo largo del tiempo y siguen en funcionamiento bajo regadío para producir maíz.

\section{Excavación de la cala 02 en Sillitu - Sector de Chimpa}

La cala 02 de $1 \mathrm{~m}$. x $1 \mathrm{~m}$. excavada en el subsector de andenes de Sillitu - Sector Chimpa, se ubica en el andén № 4 a una altitud de 3,498 m.
Su localización exacta es: UTM (WGS 84): 18L 0612683 - 8408798.

Se decidió trabajar en el andén № 4 del sub-sector denominado Sillitu debido a que su muro de contención presentaba la boca de salida de una canaleta subterránea que atraviesa lo atraviesa. Queríamos documentar el drenaje interno del andén a través de este canal y conocer detalles acerca de su técnica constructiva y de su probable época de construcción, uso y mantenimiento. Se procedió entonces a realizar una cala de $1 \mathrm{~m}$ x $1 \mathrm{~m}$. a unos $20 \mathrm{~cm}$ del muro del andén № 4.

La excavación de esta cala permitió documentar la parte final de la canaleta y comprobar que se trataba de una ducto de drenaje interno del andén № 4, el cual tenía conexión directa y recogía las filtraciones de los andenes № 4 y № 5 .

La cala permitió además documentar la técnica constructiva del canal que posee un lecho o cama hecho de mortero de barro y arcilla, y,

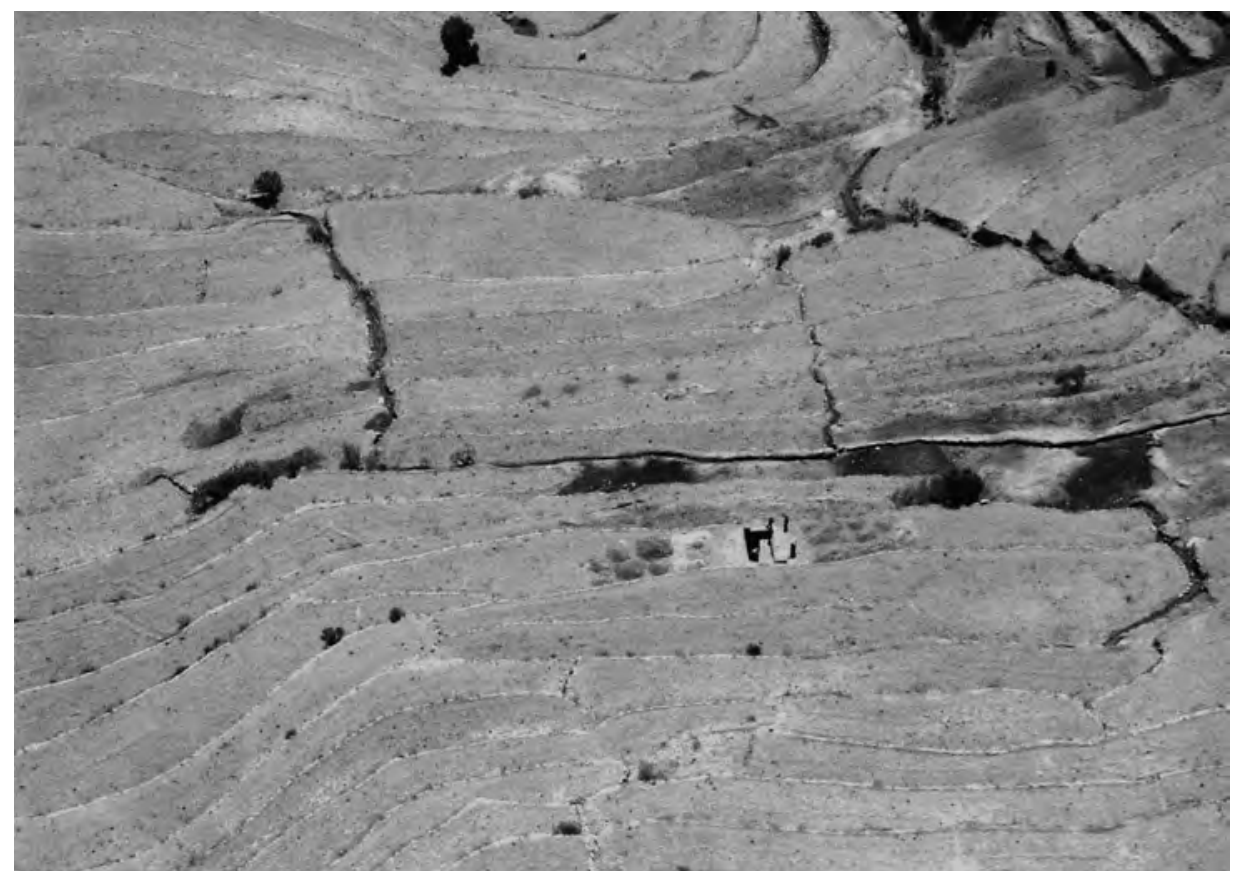

Foto 5. Panorámica del sub-sector de andenes de Sillitu visto desde la parte superior en la que se observa la ubicación de la trinchera № 01. Se puede observar la cuidadosa separación de los suelos en montículos excavados de los andenes, siguiendo el orden en que fueron extraídos para su reposición al final del trabajo, tal cual fueron encontrados en la estratificación antes de nuestras intervenciones. 

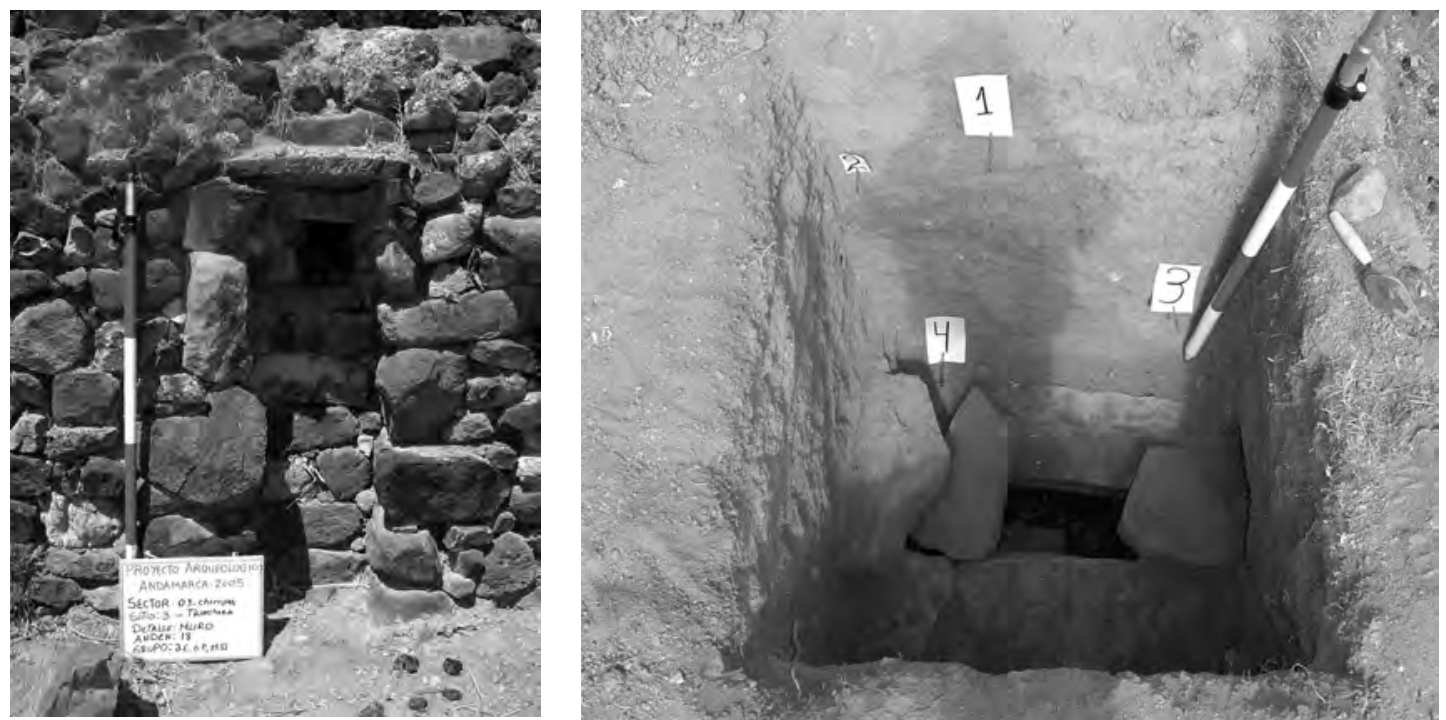

Foto 6. Boca de la canaleta en la cara del muro llamada "Paccha" por los andamarquinos.

Foto 7. Cala 02 excavada en el sub-sector de andenes de Sillitu - Sector de Chimpa. Se aprecia la parte final de la canaleta de drenaje subterráneo cercana a su desembocadura en el muro de contención del andén № 4 .

lajas de piedra que forman la solera y los muros laterales del canal así como las tapas del mismo. Este mismo mortero recubre las paredes y el techo de lajas del canal evitando así la pérdida de agua por filtración. Por otro lado, los perfiles de la cala revelaron cómo el andén № 4 también había tenido varias etapas de refacción detectándose nítidamente tres de ellos, todos tardíos.

Excavación de la Trinchera № 01 en el sub-sector de Silitu - Sector de Chimpa

La trinchera № 01 (UTM - WGS 84: 18L 0612683 - 8408798) se excavó en el andén № 4, a una altitud de 3,498 m., en el sector de andenes de Chimpa, sub-sector de Sillitu.

La cala prospectiva № 02 había mostrado el potencial informativo del andén № 4 respecto a la complejidad de las capas interiores de los andenes así como acerca de la existencia de un sistema de drenaje interno que hasta ahora no habíamos podido documentar en detalle. Esa es la razón por la cual decidimos que esta cala 02 diese lugar a la excavación de la trinchera 01 como una ampliación de la primera intervención.

Nuestro trabajo de excavación se vio así facilitado por el conocimiento previo que teníamos de las capas que componían la estructura interna del andén. La excavación de la trinchera № 01 tuvo $2 \mathrm{~m}$ de ancho, y el trabajo se realizó de manera perpendicular a los muros de los andenes № 4 y № 5 . Esto facilitó la documentación del canal de drenaje y puso en evidencia una larga secuencia de eventos nunca registrados anteriormente en ningún andén. Una relación de 41 contextos ha sido documentada en su interior.

$\mathrm{Al}$ terminar de excavar la trinchera, al andén № 4 que tenía casi $5 \mathrm{~m}$ de ancho y llegó a tener de $2.40 \mathrm{~m}$ de profundidad, medidos desde el nivel superior de la capa cultivable (parte alta de la plataforma) hasta el nivel inferior del terreno natural excavado con la técnica de corte en gradas.

El andén № 4 también tiene un canal lateral que corre paralelo al muro del andén $\mathrm{N}^{\circ}$ 5 , en la parte de la plataforma adyacente a la base del muro del mismo. Una extensión de la excavación de $1 \mathrm{~m}$. x $1 \mathrm{~m}$. fue realizada hacia el Norte para documentar los contextos del otro lado del canal de drenaje principal para ver si en el otro extremo también existía el mismo canal colector lateral. 


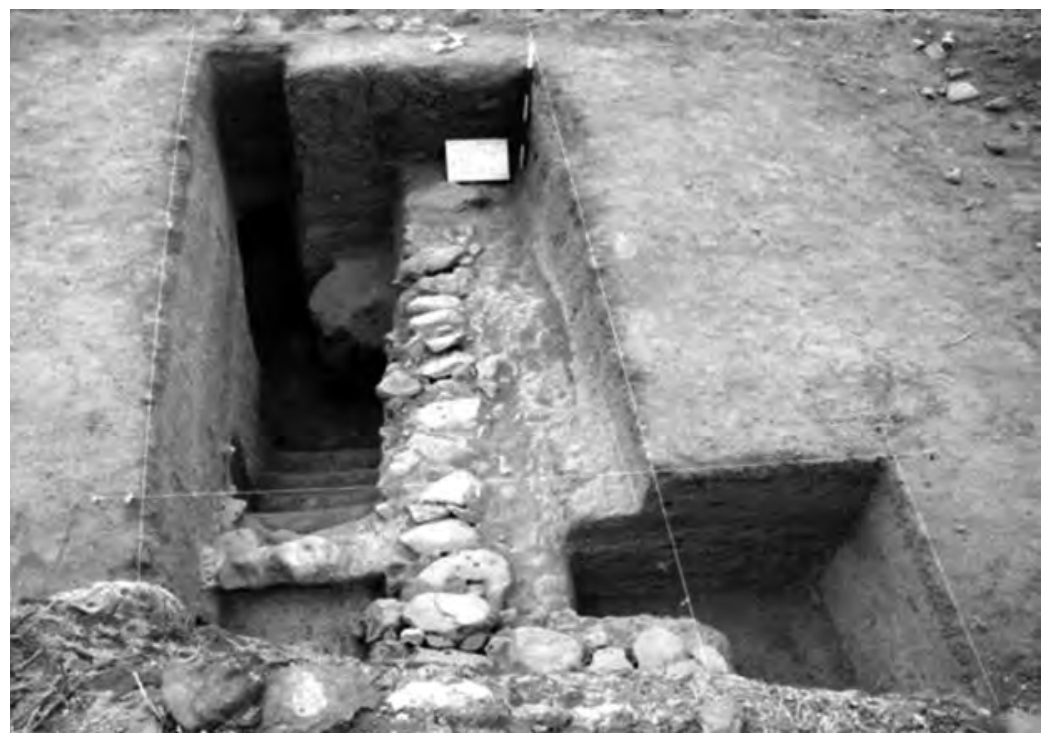

Foto 8. Vista en planta de la excavación de la trinchera № 01 en el sub-sector de Sillitu - sector de Chimpa. Se aprecia la estratificación del andén $N$ o 4, la canaleta de drenaje subterráneo hallada en su interior y los canales laterales adosados al muro de contención del andén № 5 .

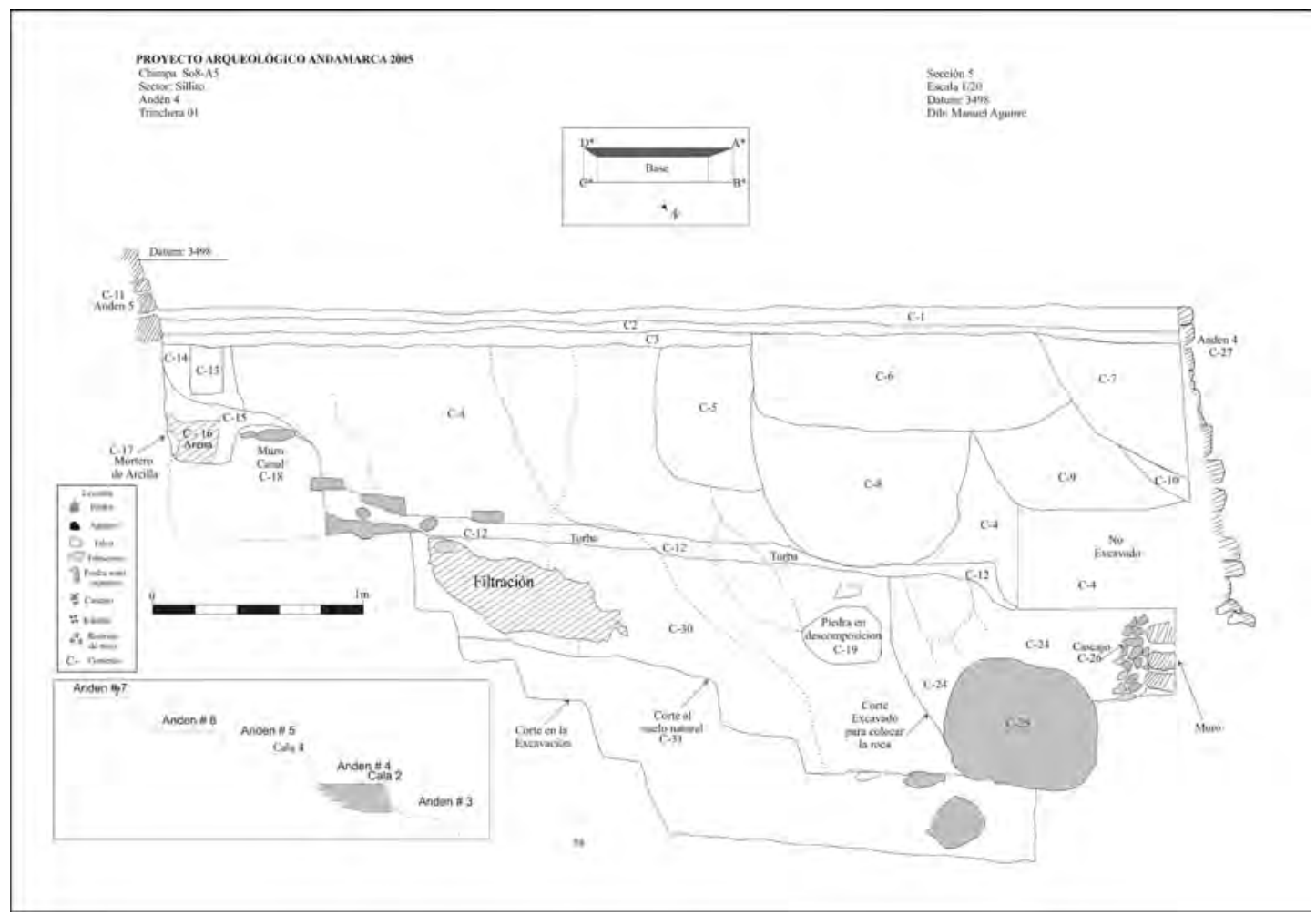

Gráfico 7. Dibujo del Perfil Sur de la excavación de la trinchera № 01 en el sub-sector de Sillitu - Sector de Chimpa. Achurada, las filtraciones de agua no retenidas por el canal de drenaje subterráneo. La gran piedra en gris fue colocada intencionalmente para controlar la presión hidrostática y evitar la caída del muro de contención durante el riego y saturación de los capas de suelos interna del andén № 4. Nótese también la capa de cascajo colocada detrás de la cara interna del muro del andén. 


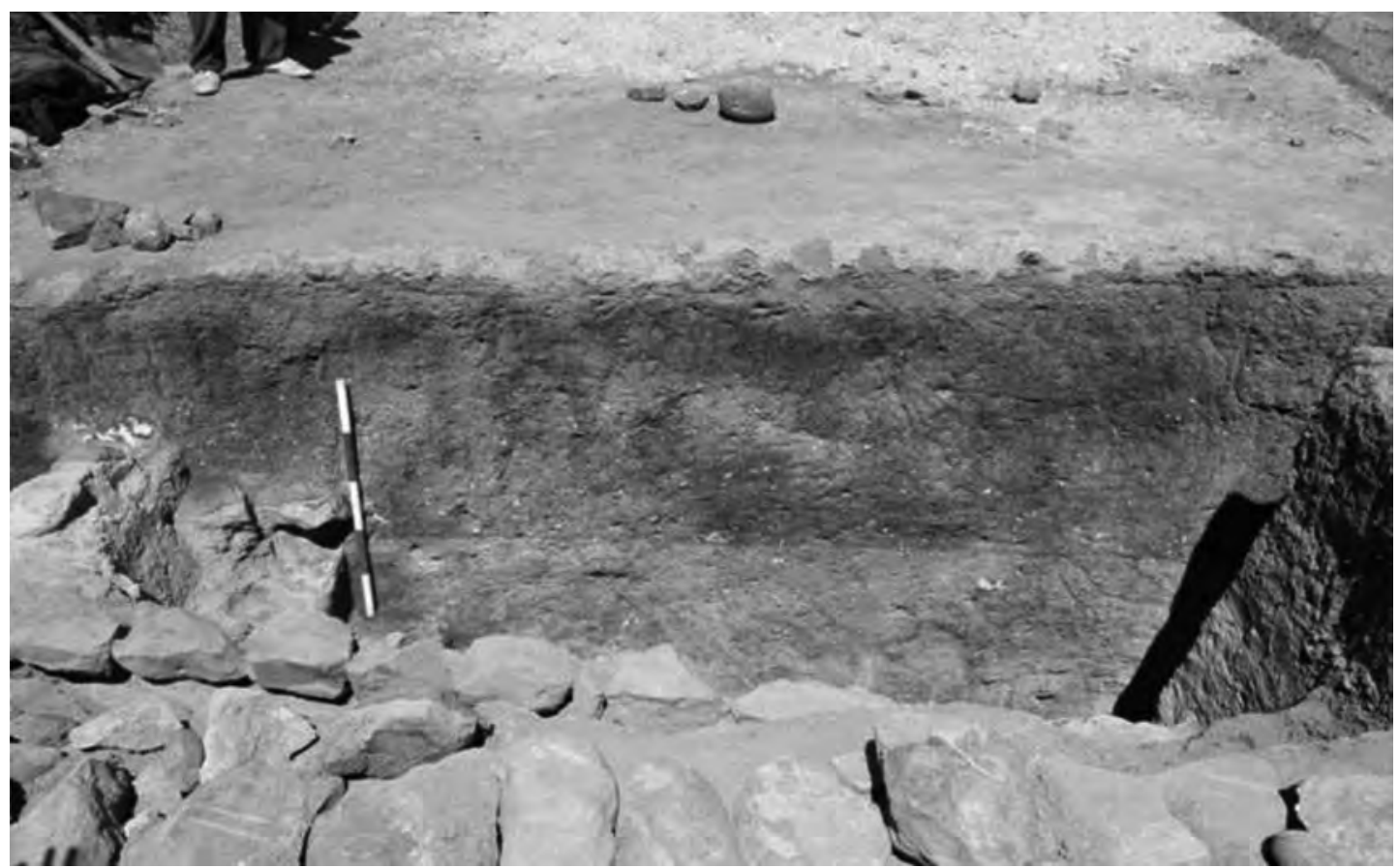

Foto 9. Detalle del perfil Sur de la excavación de la trinchera № 01 en Chimpa. Nótese la diferencia de color entre las tres capas presentes en la estratificación.

Finalmente, una cala de $40 \mathrm{~cm}$ de ancho, a partir del contexto № 24 a 2 m de profundidad fue realizada hacia la cara interna del muro de contención del andén № 4, encontrándose una capa de cascajo adosado a éste cercana a la base del muro.

La trinchera 01 excavada en el sub-sector de Sillitu, Sector de Chimpa, ha ofrecido excelentes resultados en cuanto a la información recogida y procesada acerca del sistema de drenaje de los andenes. Efectivamente, la canaleta interna principal que ha sido objeto de investigación no drena solamente el andén donde se ubica físicamente. Sirve también para evacuar el agua excedente del andén superior № 5 hacia la plataforma del andén № 3, evitando así que la presión hidrostática afecte al andén donde se integra, optimizando el uso del agua cuando se lleva a cabo el regadío o llueve excesivamente.

Un canal lateral colecta las filtraciones que no alcanzan a ser captadas en las capas superio- res del andén № 5 y las hace llegar al canal de drenaje principal del andén № 4. Esta canaleta de drenaje del andén № 4, no sólo abarca los andenes presentados en este informe en el subsector de andenes de Sillitu, sino que existen en varios de los sectores de andenes de Andamarca. Conforman un articulado y sofisticado sistema de drenaje, captación de excedente de agua de regadío y su redistribución a andenes inferiores desde la parte más alta cercana al canal de irrigación principal hasta la parte inferior de los andenes cercanos al cauce del río.

Sin embargo, las canaletas de drenaje no aparecen en todas las sub-sectores sino que se presentan en los andenes según las necesidades y características de los suelos y subsuelos de cada sub-sector.

Variantes de carácter geológico, hidrogeológico y topográfico están en el origen del problema de la saturación de agua de este sub-sector. Este problema fue solucionado a través de la 


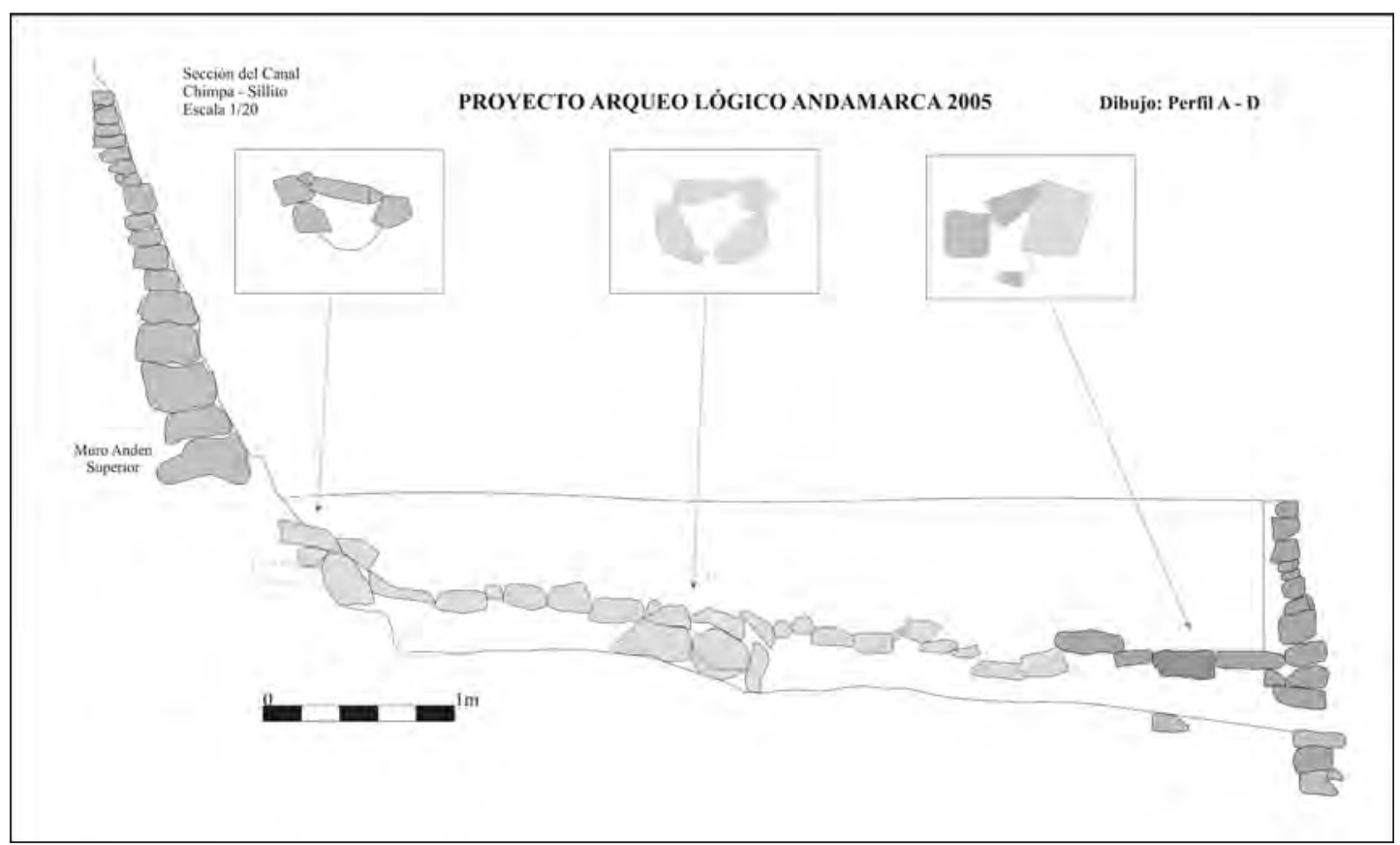

Gráfico 8. Dibujo del perfil Norte de la trinchera № 01 en el sub-sector de Sillitu - Sector de Chimpa. Se aprecia el corte en sección de la canaleta de drenaje interna del andén $\mathrm{N}$ o 4 y dibujos de tres secciones transversales de la misma. La primera (A) cercana al muro de contención del andén № 5, la segunda (B) en la parte central de la canaleta, y, la tercera (C) cercana a la cara interna del muro de contención del andén № 4.

construcción de este sistema de drenaje interno de los andenes.

En resumen, el suelo natural de la ladera del cerro fue cortado en escalera o gradas para iniciar la construcción del andén, colocando la gran piedra mencionada para ayudar en la estabilidad del muro de contención. Enseguida, fueron colocadas como rellenos dos gruesas capas de suelo de diferente composición, las cuales conforman la plataforma del andén, y, sobre ellas, se colocaron tres capas más de suelos: dos capas de suelos agrícolas no enriquecidas primero y una capa de suelo agrícola seleccionado con mayor cantidad de material orgánico (guano) cerca de la superficie la cual está preparada para la actividad agrícola.

El canal de drenaje se construyó entre las dos capas inferiores y más gruesas del andén. Su sección es cuadrangular. Está construido con lajas de piedra en la base, muros laterales y techo.
Toda la obra de arte, está recubierta de mortero de barro, constituido en gran proporción por material arcilloso, colocado intencionalmente para impermeabilizar la canaleta y evitar la pérdida de agua por filtraciones desde su interior. El aprovechamiento del agua se optimiza y prueba de ello es la aparición de la filtración de agua en las capas inferiores del andén sin necesidad de riego en la superficie. Para terminar sobre este punto, el muro del andén presenta adosado a su cara interna rellenos de cascajo de tamaño medio y grande que facilita el drenaje del agua hacia el andén inferior.

Un detalle sobresaliente del andén con un muro de contención de casi $2.50 \mathrm{~m}$ de altura, es que al excavar la ladera del cerro en gradas o escalones para comenzar la construcción del andén, se colocó una enorme roca en la parte inferior de la primera capa de relleno. La intención fue controlar la presión hidrostática que podía 


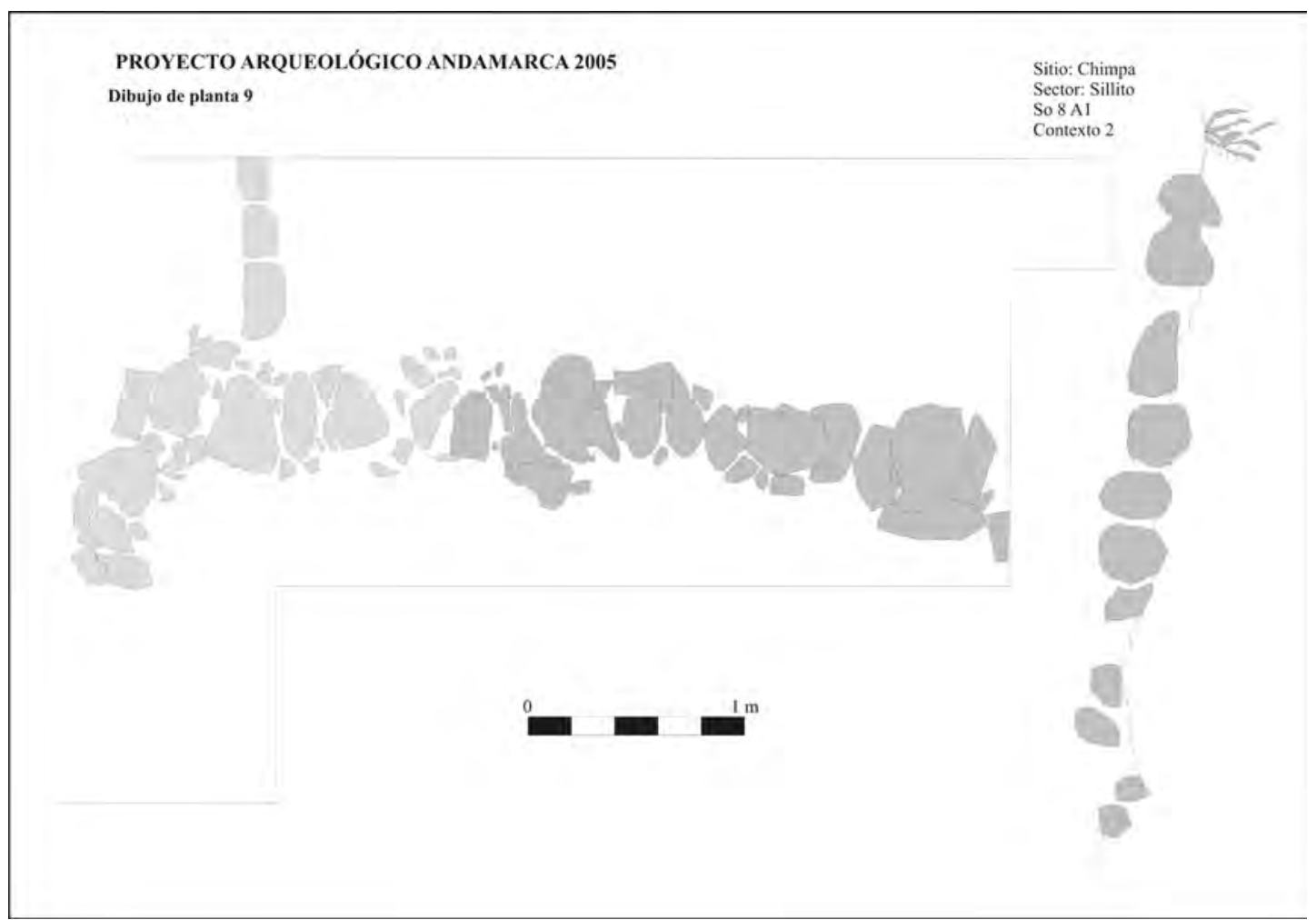

Gráfico 9. Dibujo en planta de la canaleta de drenaje interna del andén № 4 .
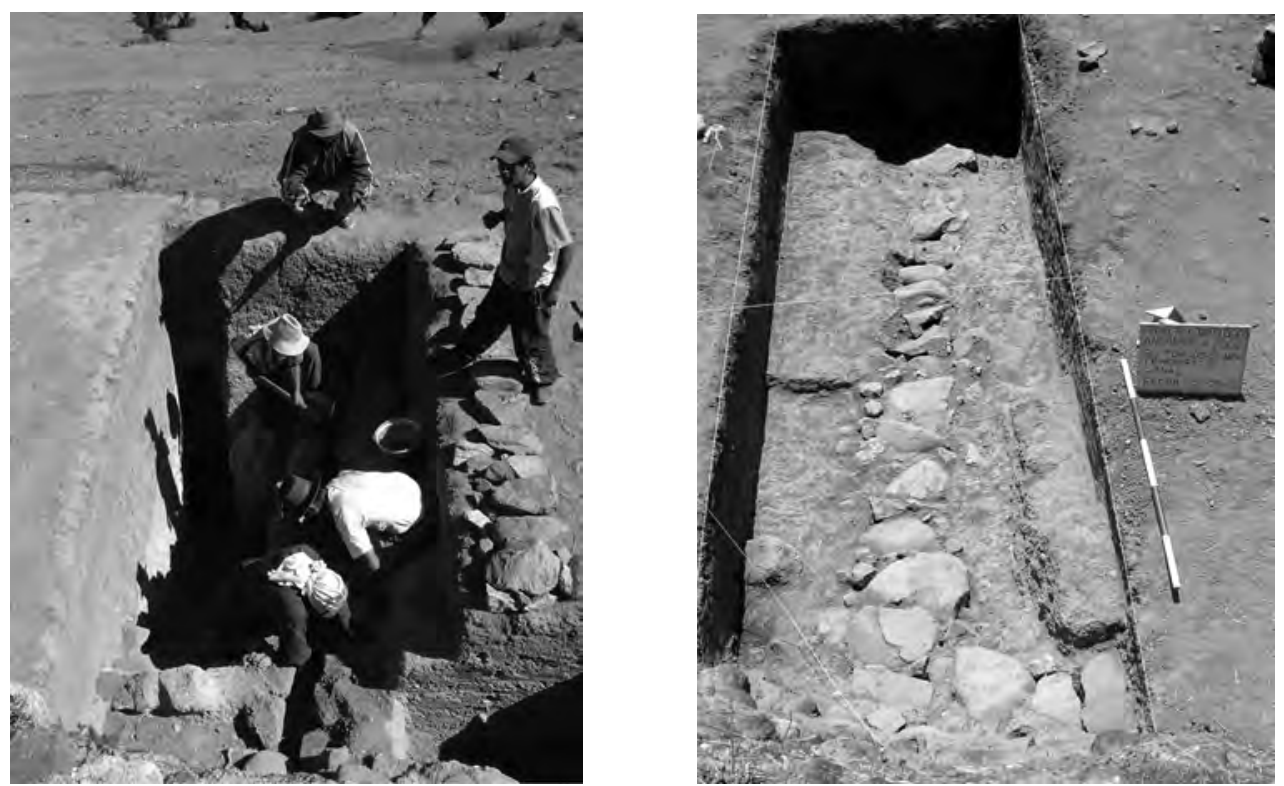

Foto 10. Rehabilitación y consolidación del canal de drenaje subterráneo del andén № 04 en el sub-sector de Sillitu - Sector de Chimpa. 
hacer desplomar o colapsar el muro de contención a la hora de recibir y saturarse por agua durante el riego. Queremos añadir que el agua que se llega a filtrar está contenida en la capa inferior de suelo del andén y que cada día el calor del sol calienta el subsuelo, el agua contenida en esa capa sube hacia los niveles superiores por capilaridad, brindando la humedad necesaria a las raíces de los cultivos, actuando como una especie de tanque de almacenamiento de líquido elemento. Tales niveles de precisión técnica en el diseño de un andén no han sido registrados antes en ningún trabajo arqueológico.

\section{El sector de andenes de Huaylla}

El sector de andenes de Huaylla se ubica en la parte baja de la ladera del cerro Antañazo, en la margen izquierda del río Negromayo, a la altura del kilómetro 62 de la carretera Puquio -Andamarca. Su extensión total es de 12 ha. las cuales recubren la ladera del cerro desde el cauce del río, en un sub-sector denominado Lambracha, ubicado en el piso ecológico Quechua, hasta la parte alta denominada Huaylla Pata en el piso ecológico Suni. Haciendo el conteo de abajo hacia arriba, la carretera citada corta el sistema de andenes a la altura del muro del andén 37. El canal de regadío de Nawinpuquio dota de agua a este sector de andenes y recorre para irrigarlo $8.20 \mathrm{~km}$ desde el manantial que es su fuente natural de captación de agua.

En cuanto a la construcción de los muros de contención, éstos mantienen una forma irregular en lo que refiere a la distribución de las piedras, teniendo el aparejo del muro una edificación progresiva ascendente, es decir, habiéndose colocado las piedras más grandes en la base del muro formando la cimentación del andén y aquellas piedras de menor tamaño en la parte media y alta del mismo. La inclusión de cuñas como parte del aparejo del muro brinda estabilidad a la estructura. El sitio arqueológico más importante asociado a éste sistema de andenes es el de Canichi, cercano al pueblo actual de Andamarca. Sin embargo, en los recorridos prospectivos previos a la excavación de la trin-

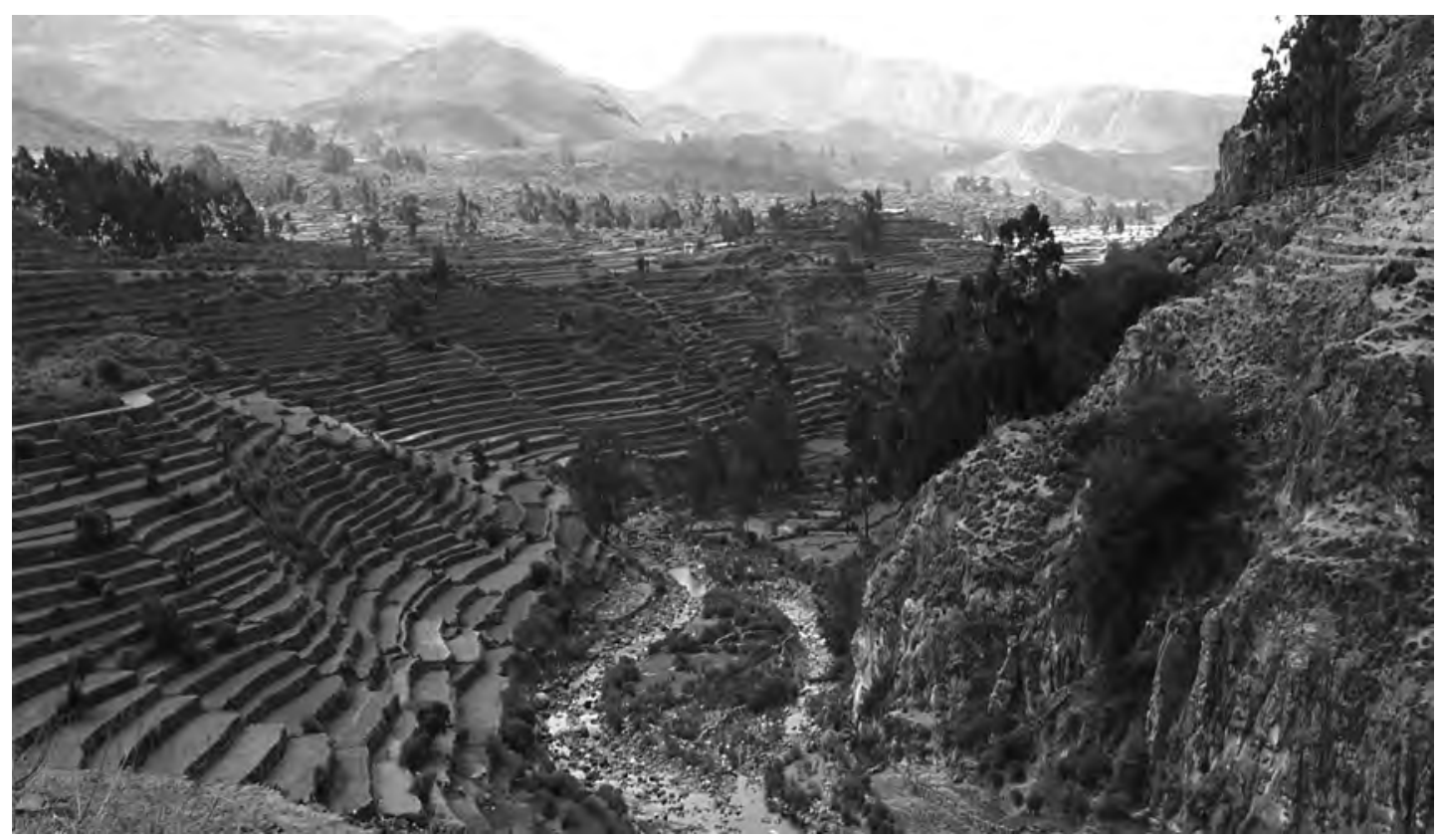

Foto 11. Cauce del río Negromayo con los andenes del sector de Huaylla ubicados en la margen izquierda por debajo del nivel de la carretera. 
chera 01 en este sector, se identificó un poblado más temprano en la ladera del cerro, en un subsector vecino al de los andenes de Lambracha, en el lugar denominado Moqo, a unos $50 \mathrm{~m}$ al Sur de la excavación.

\section{Excavación de la Trinchera 01 en el sub-sector de Lambracha - Sector de Huaylla}

La Trinchera 01 excavada en el sector de Huaylla, se ubica en el Andén № 33, en el sub-sector denominado Lambracha, a una altitud de 3,500 m en el piso ecológico Quechua. Su localización geográfica exacta es UTM: L18 0612049 - 8407576.

En la base del muro de contención del andén № 33 existe un canal de riego construido por una hilera de piedras unidas por mortero de barro que canalizan el agua y que posibilita el riego por inundación de la plataforma del mismo. El muro de contención de este andén №

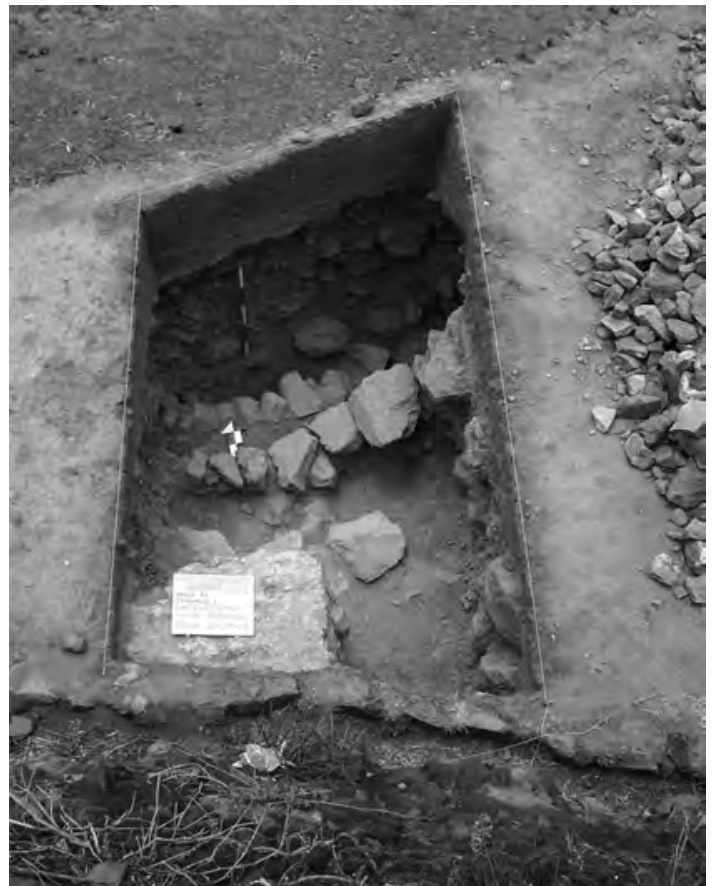

Foto 13. Detalle de la trinchera № 01 excavada en el andén № 33 en el Sector de Huaylla donde se aprecian los dos muros asociados a la chullpa la cual se ubica al Este.

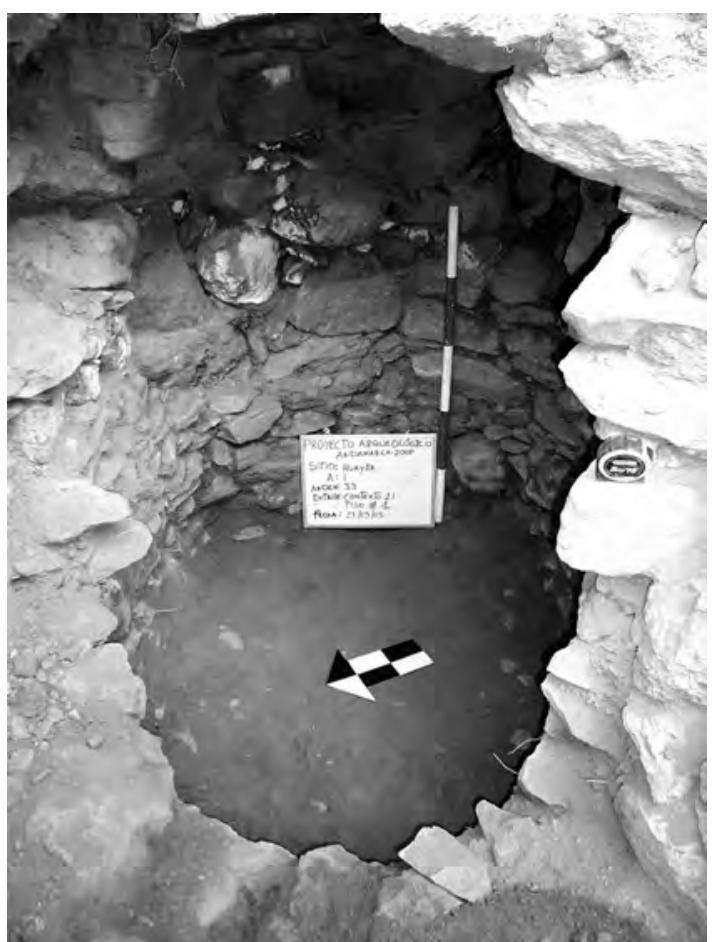

Foto 12. Chullpa ubicada al interior del andén № 33 en el Sector de Huaylla.

33, presenta una mampostería irregular, es decir, que hacia la sección Norte del andén, se aprecia una construcción celular caracterizada por piedras grandes y piedras pequeñas dispuestas a su alrededor. Esta parte del muro está delimitada por unas graderías que se encuentran en la esquina Norte. Estas graderías están hechas sobre el afloramiento de una roca del subsuelo y fue aprovechada para esta función por su ubicación, la cual impide la producción agrícola en esa parte de la plataforma. El muro de este andén es vertical $\left(90^{\circ}\right)$ en toda su extensión. El aparejo del muro de contención del andén muestra en general una construcción progresiva ascendente, en la cual las piedras más grandes se encuentran en la base, las medianas están en la parte central y las más pequeñas en la parte superior, cercanas al nivel de la plataforma. Del mismo modo, se utilizó cuñas de piedra y mortero de barro para unir las piedras del muro y darle estabilidad. 
El andén presenta 03 capas agrícolas de suelo seleccionado y varios niveles de relleno al interior de la plataforma del mismo. El suelo natural del cerro ha sido excavado previamente cortado en forma de gradas para iniciar la construcción del andén, su muro de contención y sus capas internas. El hallazgo excepcional de una chullpa al interior de la estructura de la terraza representa un caso muy singular para entender la correlación de eventos naturales y sociales ocurridos en este sector así como la secuencia cronológica de construcción de los andenes.

Ha quedado documentado, que como parte de las edificaciones allí existentes se construyó una estructura a manera de silo o pequeña chullpa. Esta edificación de planta ovalada fue construida con piedras canteadas unidas con mortero de barro. El techo fue construido con la técnica de "falsa bóveda". Presenta dos momentos constructivos en donde las bases y muros laterales de la sección inferior difieren en su mampostería de aquellos de la sección alta de la chullpa. Una parte de dos muros paralelos, asociados a la chullpa, han sido también documentados dentro del andén. Se trata de dos estructuras ligeramente arqueadas que tienen dos y hasta tres hileras de piedras canteadas unidas por mortero de barro. Para su construcción se excavaron zanjas para ubicar los cimientos. Las estructuras presentes dentro del andén evidencian varios momentos de ocupación. Lamentablemente, no conocemos el periodo en que se construyó esta edificación debido a la ausencia de otros materiales arqueológicos diagnósticos asociados. Por su ubicación estratigráfica, planteamos que podrían corresponder a un poblado Huari y/o Rucana ${ }^{9}$.

La excavación del andén № 33 en Lambracha, en el sector de Huaylla, ha permitido establecer una secuencia preliminar en la construcción de los andenes. Todo indica que antes de que este sea un sector destinado a la agricultura existió aquí un asentamiento doméstico. Este asentamiento, cuyo núcleo fue el sitio de Moqo, pequeña colina ubicada a $50 \mathrm{~m}$ al Sur de la excavación, fue construido a través de la conformación de terrazas en toda la ladera del cerro aproximadamente desde la carretera actual hasta el propio cauce del río.

Asimismo, como parte del relleno que conforma el interior del andén, ha sido identificada una capa o nivel producido por una fuerte escorrentía de origen aluvial. A partir de los análisis in situ de los perfiles de la excavación realizados por el geólogo del proyecto, Lic. Guillermo Maldonado, se ha podido establecer que un gran evento de carácter erosivo destruyó parcialmente las estructuras pre-existentes. Esta escorrentía de material aluvial producida por un deslizamiento natural de suelos bajo la forma de un "huayco", destruyó parte de la chullpa y de los muros asociados a ella. Se trata de un evento natural más tardío, ocurrido posiblemente durante el Intermedio Tardío o más probablemente durante la ocupación Inca. Los materiales constructivos de la chullpa y de los muros destruidos por el huayco se reutilizaron para construir la estructura de vocación agrícola, apoyando parte de la edificación del muro de contención del andén sobre el muro de la Chullpa. El relleno de la plataforma del andén se realizó utilizando tanto materiales como piedras provenientes de las antiguas construcciones así como rellenos preparados, colocados intencionalmente para constituir y soportar la superficie agrícola cultivable seleccionada de la plataforma. Un punto sobresaliente es que la estructura de la chullpa ha sido intencionalmente rellenada para poder contener la presión de la tierra de los rellenos y el mismo muro de la chullpa forma parte a su vez, del muro del andén № 33.

9 Al comparar los materiales asignados a los chancas (Lumbreras 1974 y 2001; y Gonzales-Carré 1992), advertimos la no coincidencia con los materiales y técnicas utilizados por las sociedades ubicadas al Sur de Vilcashuamán durante el Intermedio Tardío. Para mayor detalle sobre estas diferencias en la arquitectura y la cerámica, referirse a los artículos de S. Berrocal y J. Cámara, en este mismo volumen. 


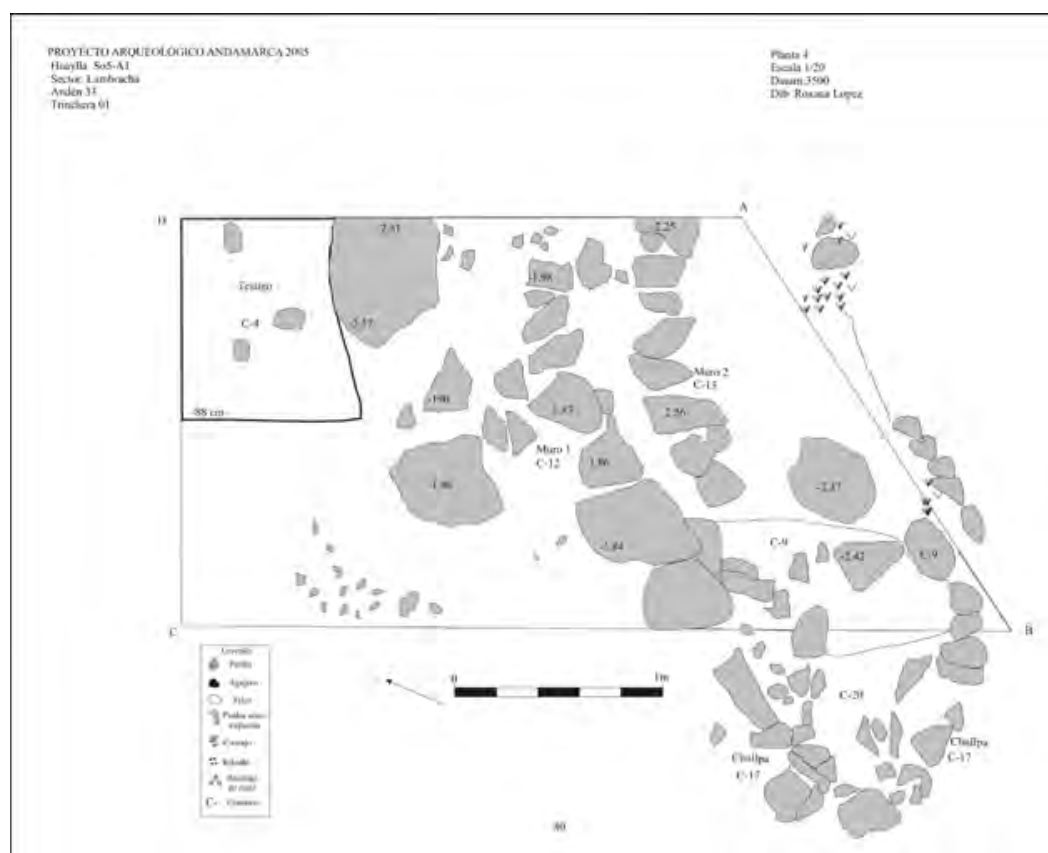

Gráfico 10. Dibujo en planta de la excavación del andén № 33 en el sub -sector de Lambracha en el Sector de Huaylla. Nótese la ubicación exacta de la Chullpa al interior del andén así como la de los dos muros asociados a la misma.

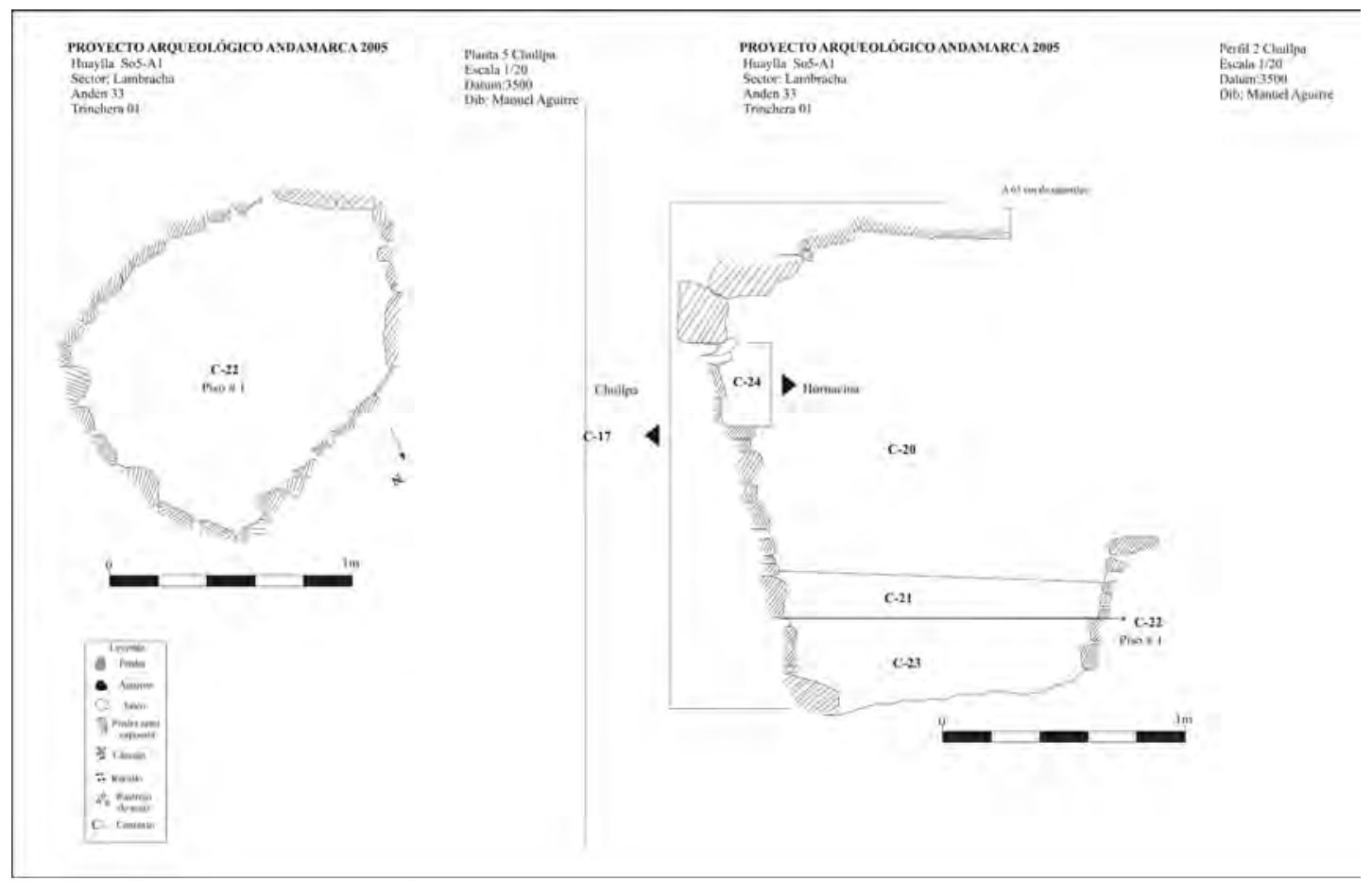

Gráfico 11. Dibujos en planta y en sección de la chullpa ubicada al interior del andén № 33 en el Sector de Huaylla. Se observa en la sección de la chullpa la identificación de cuando menos dos pisos correspondientes a ocupaciones diferentes que han sido también diferenciadas en los aparejos de las dos secciones en los muros de la chullpa. 


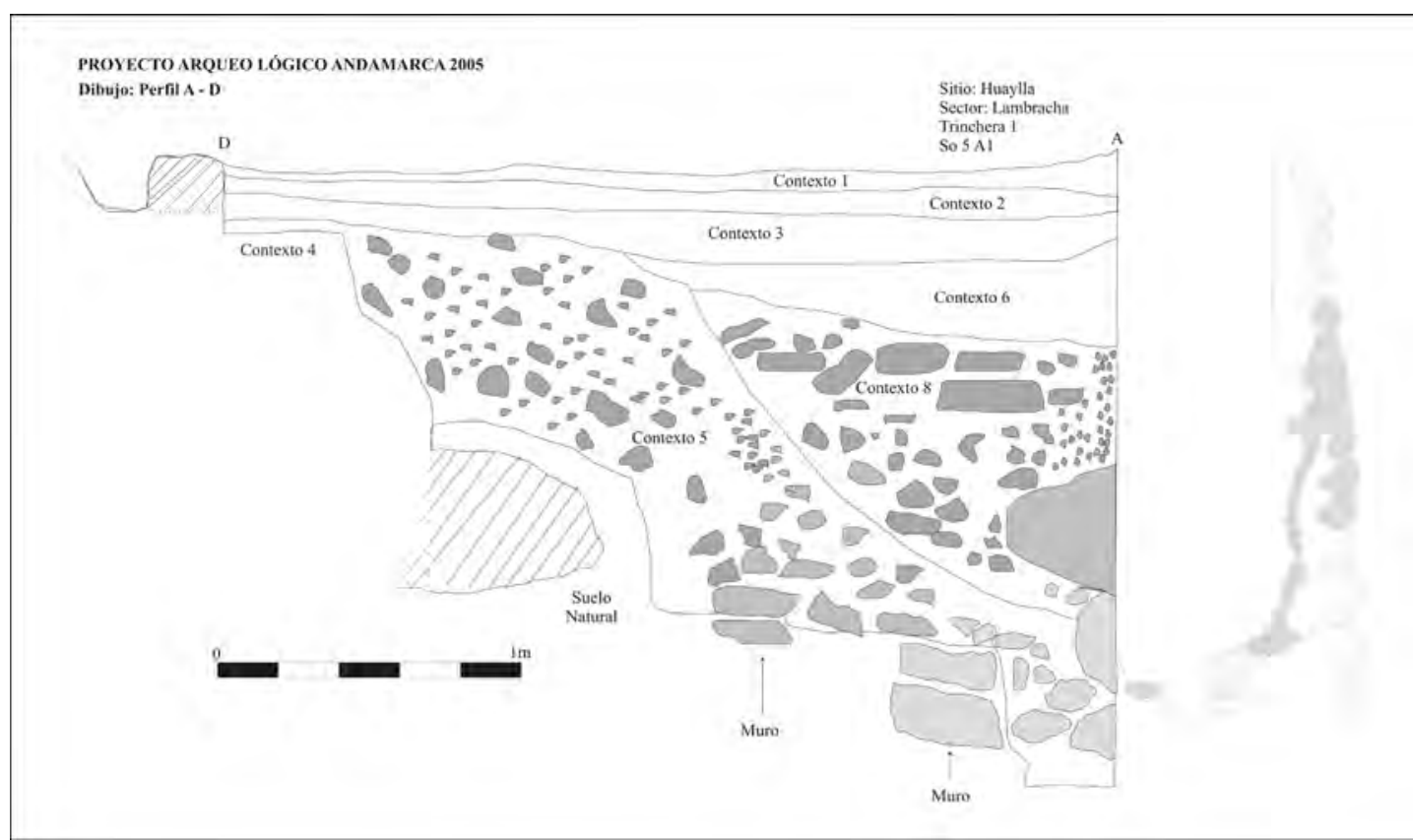

Gráfico 12. Dibujo del perfil Oeste de la excavación del andén № 33 en Huaylla. El "contexto 5" es el que ha sido identificado como el nivel o capa de la escorrentía semejante a un "huayco". Nótese también los dos muros destruidos que están asociados a la chullpa. Con fines didácticos se ha añadido a la derecha el muro de contención del andén № 33 .

Este es un claro ejemplo de como la artificialización o modificación del paisaje con fines agrícolas, a través de la construcción de andenes, cambió por completo las características previas del mismo, llegando incluso a enterrar aldeas enteras de periodos anteriores, pudiendo haber sido la destrucción de poblados anteriores y su recubrimiento con andenes, una estrategia de carácter ideológica y política utilizada en la ocupación imperial de una nueva región conquistada por los Incas, o, simplemente, consecuencia de la necesidad de ampliar la frontera agrícola para incrementar la producción.

\section{El sector de andenes de Tucuta}

El sector de andenes de Tucuta se encuentra en la parte alta del valle del río Negromayo, por encina del límite superior de cultivo actualmente dedicado al maíz. Por su altitud (3,675 m), este paraje se ubica en el límite entre los pisos ecológicos Quechua y Suni. Los andenes que con- forman este sector se extienden sobre 21.5 ha. El canal de Vizca llevaba eventualmente el agua para la irrigación hasta este sector de andenes recorriendo $20 \mathrm{~km}$. En la actualidad, el canal y los andenes sufren un proceso de abandono y no cuentan con abastecimiento de agua, razón por la cual son utilizados como terrazas de secano. El sitio arqueológico más cercano asociado a este sector es llamado Marka Marka, siendo su filiación Rucana (Intermedio Tardío), y se ubica 50 $\mathrm{m}$ por encima de los andenes mencionados. La localización exacta de las excavaciones realizadas es la siguiente:

Trinchera 01 (andén № 9):

UTM: L18 0612467 - 8405692. Altitud: 3,675 m. Trinchera 02 - (andén № 8):

UTM: L18 0612467 - 8405692. Altitud: 3,673 m.

El interés de excavar en este sub-sector de Tucuta llamado Llosllasqa, fue documentar andenes de probable filiación Rucana construidos durante el Intermedio Tardío. Los resultados de 


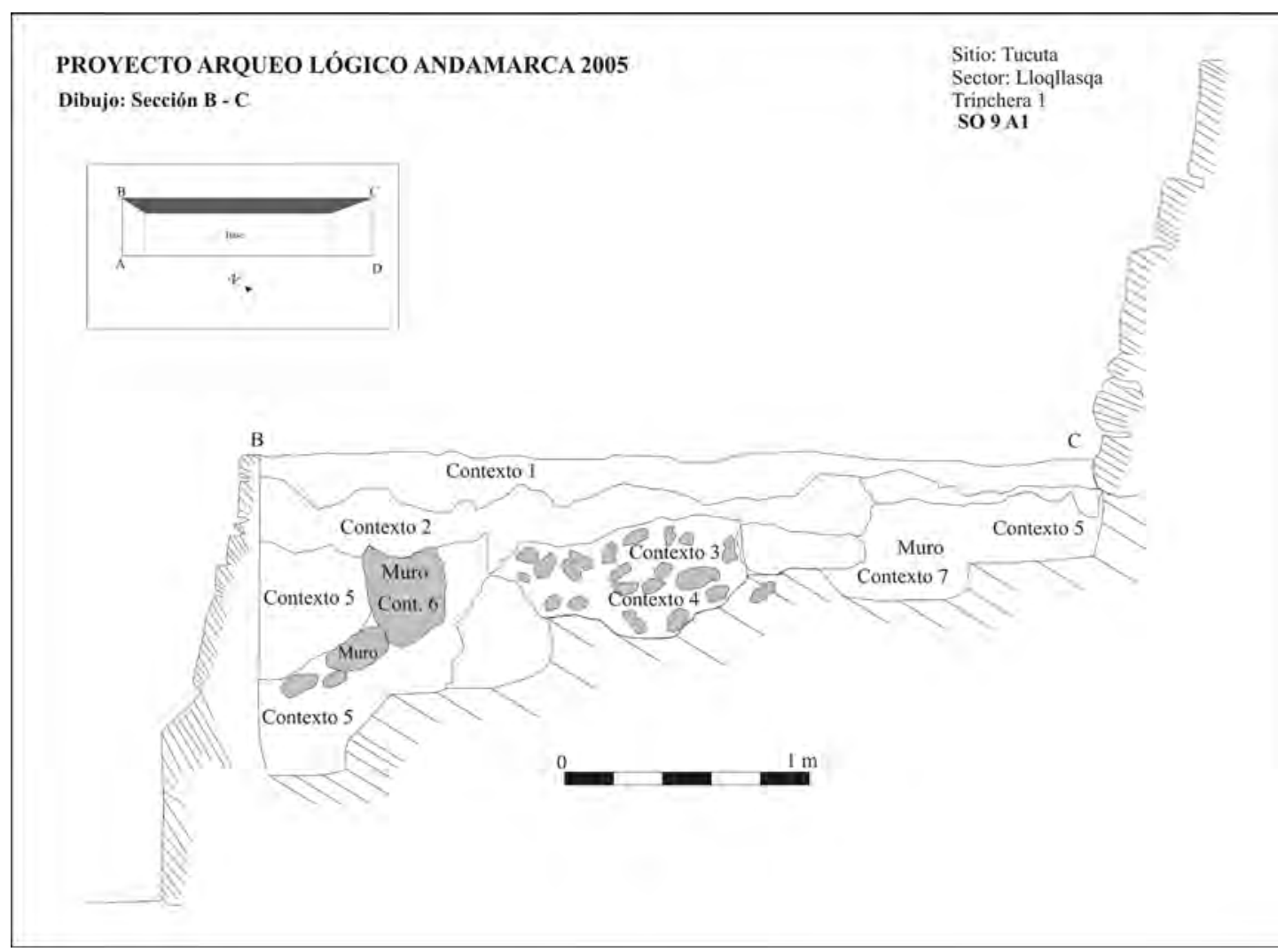

Gráfico 13. Dibujo del perfil Norte de la trinchera № 01. Nótese la ubicación de las dos estructuras al interior del andén № 9.

la excavación confirman la existencia de cuando menos dos etapas constructivas en los andenes. En este caso, no se trata de la sobreposición de secciones de los muros como parte de la (re) construcción de un mismo andén -como en el caso de los andenes de Chimpa-, sino de muros que aparecen en la excavación al interior de las trincheras № 01 y № 02 a intervalos regulares de $2.70 \mathrm{~m}$. Precisamente la necesidad de confirmar la existencia de muros a distancias regulares unos de otros, similares al primero aparecido en el andén № 9 de la trinchera № 01, nos obligó a realizar la extensión de la excavación hacia el andén inferior № 8 que hemos denominado trinchera № 02 (extensión de trinchera № 01).

Como ya se ha mencionado, durante las excavaciones aparecieron muros de edificaciones ubicados enterrados dentro de los andenes intervenidos, los que evidenciaron la existencia de estructuras previas.

La construcción de los muros en sí misma presenta un patrón muy rústico si se les compara con los de lo demás sectores de andenes. Grandes bloques dispuestos de forma irregular conforman los muros que por lo general son más bajos y no alcanzan $1.20 \mathrm{~m}$ de altura. Sin embargo, si bien estos muros subyacentes se hayan equidistantes entre sí, su factura es más rústica. Estos últimos, están construidos con piedras unidas con mortero de barro y no son rectos sino ligeramente arqueados y se presentan con otros elementos arquitectónicos asociados cuya función no ha sido posible definir con exactitud. Las evidencias referidas no nos permiten por tanto, asegu- 


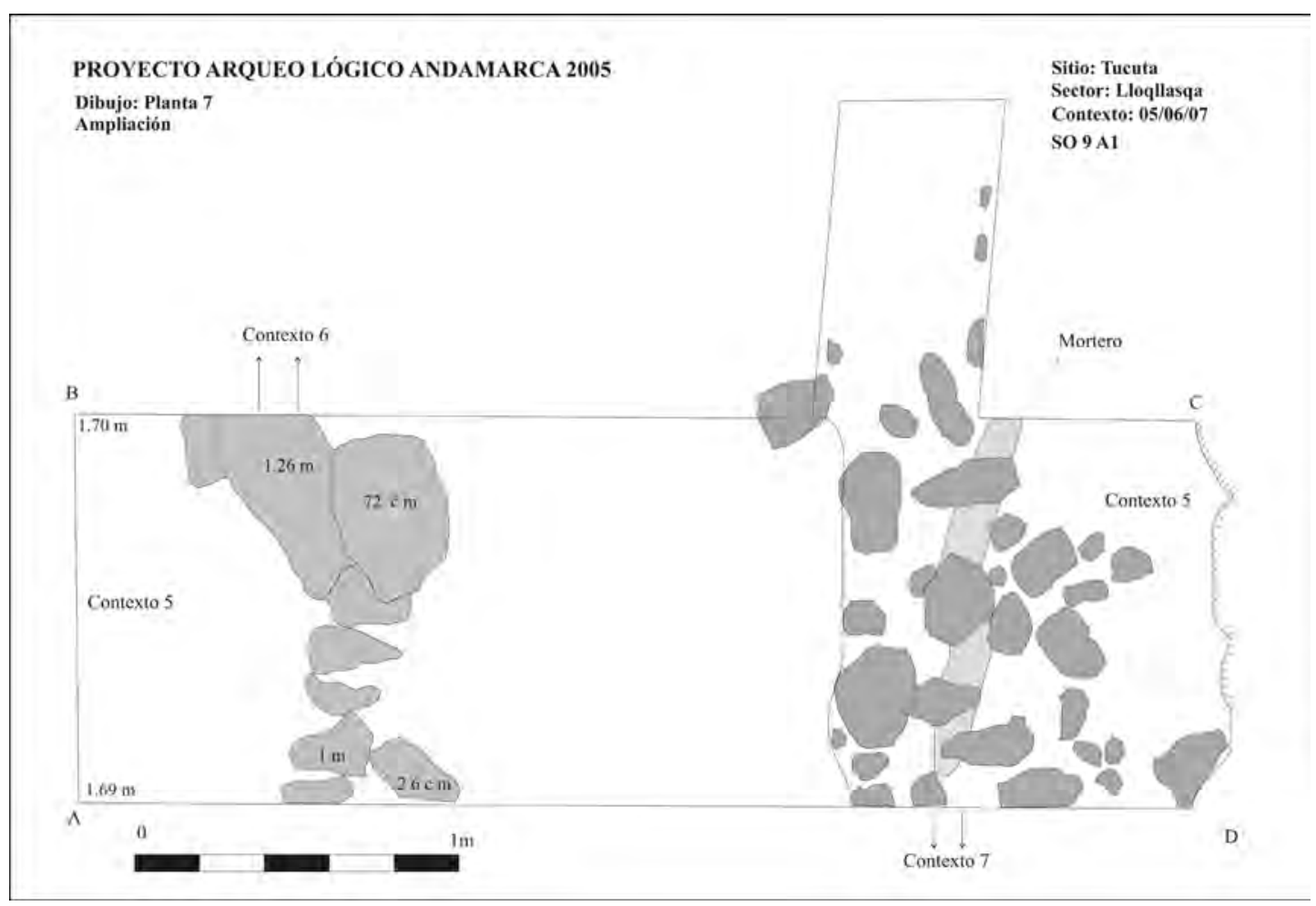

Gráfico 14. Dibujo en planta del andén № 9 en el Sector de Tucuta con la ubicación de las dos estructuras ubicadas al interior del mismo.

rar la vocación agrícola de las terrazas ya que también podría tratarse de estructuras de carácter doméstico. La configuración de los rellenos que conforman las plataformas de los andenes está marcada por la presencia de abundante cascajo grande y clastos angulares mezclados con tierra areno-limosa con contenidos escasos de nutrientes minerales en las capas que componen sus suelos.

Sin embargo, esta situación puede estar en relación con el periodo de su construcción, uso y abandono inicial que debió ocurrir durante el Horizonte Medio o el Intermedio Tardío. La re-construcción de andenes en tiempos de los Incas, hipótesis reforzada por la presencia de cascajo detrás de la cara interna de los muros, puede indicar que este piso ecológico comenzó a tomar mayor importancia para la producción agrícola durante los periodos tardíos, como con- secuencia de cambios climáticos que pudieron dar lugar a la elevación de los límites superiores de cultivo (Usselmann 1986; Chepstow-Lusty 1986; Meddens 1984; Branch et al. 2007) y pudieron favorecer la ampliación de la frontera agrícola mediante la construcción de canales de regadío y andenes.

VII. Discusión: Sistemas de ANDENES PREHISPÁNICOS, ESTADOS IMPERIALES, PRODUCCIÓN AGRÍCOla y SEgURIDAD aLIMENTARIa EN lOS ANDES Centrales

Retomando la terminología: alcances para la definición de andenes y terrazas

¿Existe una diferencia entre una terraza y un andén? De ser así, ien qué radica esta diferencia? ¿Qué factores o qué elementos debemos tomar en cuenta para clasificarlos? En la mayor parte 


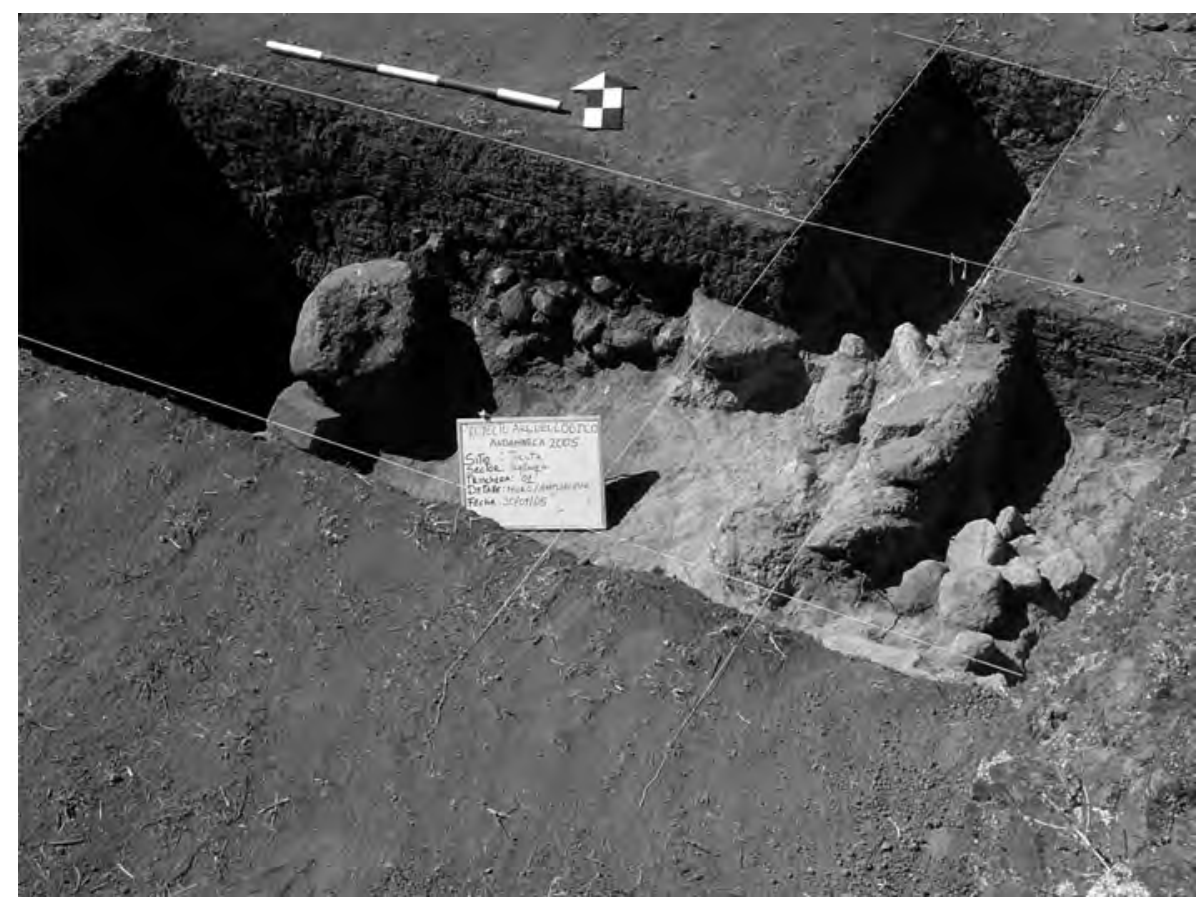

Foto 14. Trinchera № 01 excavada en el andén № 9 del sub-sector Llosllasqa-Sector de Tucuta. Nótese a la izquierda el muro de contención del andén enterrado y a la derecha la estructura de probable uso doméstico

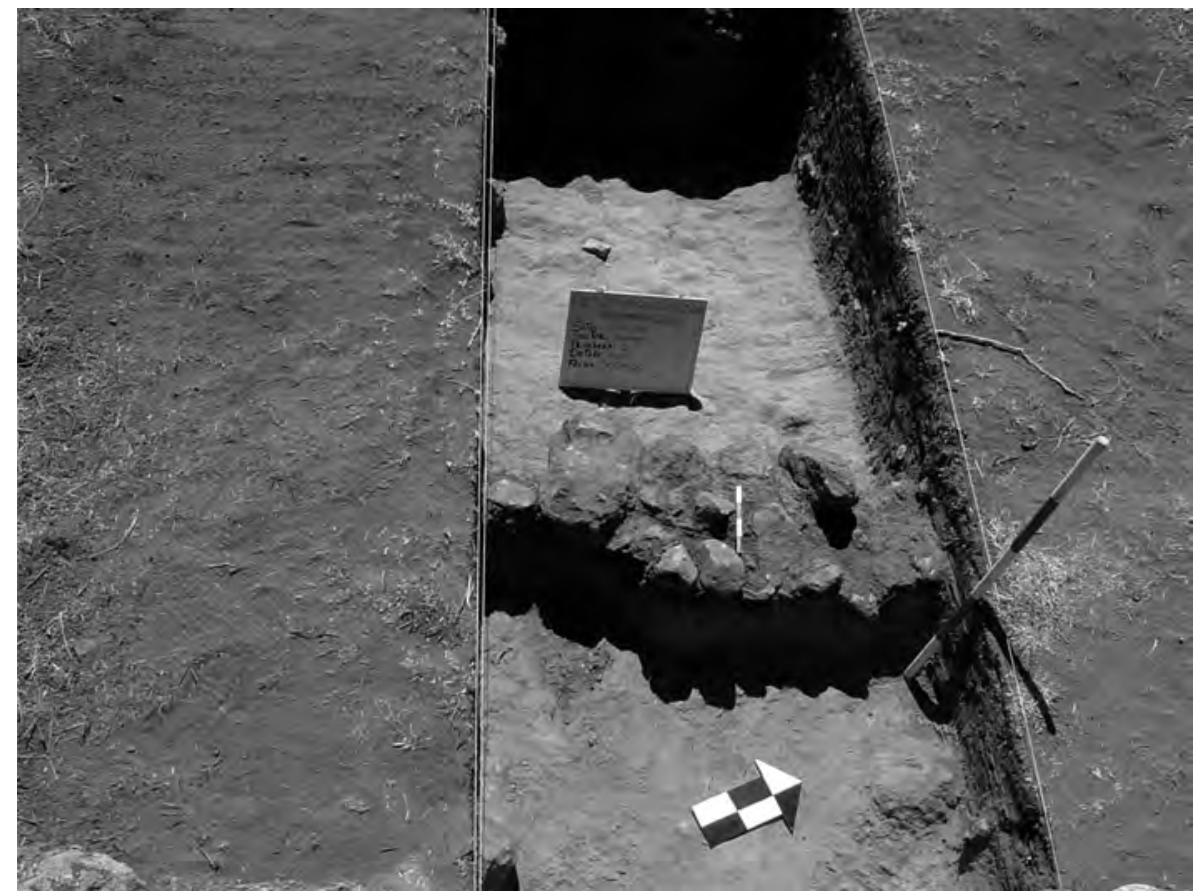

Foto 15. Excavación de la trinchera № 02 en el andén № 8 del sub-sector de Llosllasqa - Sector de Tucuta (extensión de la trinchera № 01 hacia el andén inferior). 
de la literatura sobre el particular -incluyendo esta comunicación- los términos andén y terraza han sido utilizados como sinónimos sin intentar establecer diferencias. Sin embargo, la palabra terraza ha sido utilizada por los especialistas en términos más generales englobando también la categoría de andén. Cuando hablamos de terrazas, no está necesariamente implícita una utilización de la superficie nivelada que se relacione a la actividad agrícola y bien podríamos estar describiendo un conjunto de terraplenes destinados a la ubicación de viviendas, es decir, un lugar acondicionado para tener un uso doméstico. Son numerosos los casos en que los arqueólogos hemos comprobado que lugares descritos como terrazas de cultivo resultan siendo en realidad antiguos poblados prehispánicos construidos en las laderas de los cerros. En ese sentido, cabría hacer la primera distinción entre aquellas modificaciones del paisaje natural realizando aterrazamientos con fines agrícolas y aquellas destinadas a otros fines muy diversos como aquellos realizados para proteger terrenos o poblaciones ante la eventual caída de huaycos; para el secado de productos marinos ó agrícolas; para la extracción de sal y/o para el establecimiento de vivendas en los cerros como en la propia Lima. Sin embargo, ninguna de esas distinciones o sub-divisiones funcionales atañen a la actividad agrícola.

Treacy (1994), propone que "la categoría Terraza Agrícola debe comprender a todas las formas conocidas de tierras de cultivo que han sido allanadas". Además, coincide con la descripción que hace Denevan (1987), quien indica que son superficies de cultivo artificiales, las cuales tienen una pendiente menor que la del terreno natural y poseen un muro de contención que puede ser de piedra, de barro, suelo endurecido o compuesto por vegetación.

Por su parte, el Instituto Nacional de Evaluación de Recursos Naturales (INRENA) define que "los andenes resultan de la construcción de muros de piedra de modo tal que logran modificar la pendiente de las laderas generando plataformas escalonadas de superficie plana. La mayor parte de estas estructuras cuenta con sistemas de riego; in embargo, también existen estructuras abastecidas de agua sólo gracias a las lluvias".

Para Gonzáles de Olarte y Trivellin (1999), "las terrazas serían similares a los andenes con la diferencia de que no cuentan, necesariamente con muros de piedra". Finalmente, proponen su propia definición: "los andenes y terrazas constituyen un tipo de capital natural modificado que permite prácticas agrícolas mas productivas y menos riesgosas en las zonas de laderas de montañas andinas, gracias a la conversión de terrenos en pendiente en escaleras de terrenos llanos, con irrigación controlada a través de canales o de lluvia". (Ibidem, 1999:18)

El criterio de diferenciación entre terraza y andén está sustentado para INRENA por la presencia/ausencia de muros de contención de piedra e independientemente de sus componentes estructurales podrían ser "irrigados" por canales de regadío o abastecidos por lluvias. Esta visión carece peligrosamente del criterio temporal, es decir, de la profundidad cronológica con que la arqueología opera. Andenes irrigados, hoy abandonados, bien pudieron estar en uso lo mismo que sus correspondientes canales de regadío. El hecho que hoy se presenten en estado de abandono y no los identifiquemos fácilmente en el campo no nos debe llevar a conclusiones apresuradas.

Nosotros no estamos de acuerdo con estas propuestas porque nos parecen incompletas. En primer lugar, es evidente que un paraje irrigado requiere de una infraestructura anexa que conduzca el agua hasta las parcelas de cultivo y la lluvia no representa de ninguna manera un sinónimo de irrigación. Proponemos que al hablar de terrazas, comencemos a referirnos a las estructuras agrícolas con muros de piedra o no, comprobadamente aisladas de un abastecimiento artificial de agua. Y que deberíamos hablar de andenes ó terrazas irrigadas, solo si existe asociado al conjunto de terrazas de cultivo, un sis- 
tema de abastecimiento de agua controlado. La irrigación es, por tanto, el elemento diferencial entre terraza(s) y/o andén(es). Las obras de ingeniería hidráulica necesarias para abastecer un sistema de andenes pueden ser represamientos y reservorios, bocatomas y canales de irrigación, galerías filtrantes, zanjas de infiltración, posas de disipación o canales, obras de arte en ingeniería hidráulica que permitan captar y llevar el agua desde sus fuentes hasta las terrazas de cultivo, $\mathrm{y}$ aseguren el suministro de agua permanente y controlado durante la mayor parte del año, con la excepción posible de años de extraordinaria sequía. En esto radica la diferencia, y, por tanto, queda claro que la palabra andén es inadecuada para las terrazas de cultivo por secano que se nutren de humedad a través de las lluvias estacionales y que posibilitan una sola cosecha al año.

Un segundo elemento que distingue al andén(es) de la(s) terraza(s) está relacionado con la diferencia en la calidad de los suelos. Ocurre que como las grandes obras de canalización y estructuras anexas de control y conducción del agua obedecen a un proyecto integral, conforme se avanzaba en la construcción de un tramo del canal, inmediatamente se incorporaban nuevas tierras de cultivo andenadas, en un trabajo progresivo pero acelerado (Treacy, 1994:238). Por ello, la construcción de andenes no fue el resultado de una paulatina acumulación de sedimentos del suelo local acarreados hacia la base del muro de contención por escorrentía, sino que obedecieron también a una planificación previa que incluía el diseño del muro de contención y de su estructura interna. Se constata así, como en la mayor parte de los sistemas de andenes, podemos identificar que estructuras internas que están compuestas por varios niveles o capas y obras de arte para el drenaje u otros fines tal como lo hemos descrito para Andamarca.

Un tercer elemento que distingue al andén(es) de la(s) terraza(s) se deriva de los dos primeros pero es tal vez, el de mayor significan- cia en cuanto a las posibilidades de producción y productividad. La artificialización del medio producida deteniendo la erosión y reteniendo mayor humedad crea condiciones microclimáticas favorables al desarrollo de variedad de cultivos a la par que minimiza las posibilidades de pérdidas de las cosechas por heladas o sequías (Earls 1986: 48-49; Morlon 1992).

Es muy posible que debido a este factor de mejoramiento de las condiciones micro-climáticas, muchos cultivos que hoy consideramos correspondientes a un nicho ecológico determinado hayan podido ser cultivados en zonas más altas aunque estos últimos también hayan podido variar de ubicar debido a cambios climáticos de mayor escala (Usselmann 1987).

Tomando en cuenta estas diferencias con las definiciones tradicionales, es muy posible que los sistemas de andenes pudieran producir dos cosechas con relativa facilidad para quienes supieran manejar adecuadamente los ciclos agrarios, los sistemas de control del agua, suelos y factores micro-climáticos, y articularlos con una sólida organización social en torno a las actividades agropecuarias.

Por lo tanto, entendemos a los medios técnicos de producción que denominamos andenes como un medio de producción agrícola utilizado en zonas de laderas de montañas conformado por terrazas de cultivo irrigadas. Estas poseen una estructura interna de capas y tipos de suelos sumamente compleja, y, constituyen parte de un sistema tecnológico mayor, abastecido de agua captada desde sus fuentes de manera permanente e irrigadas a través de canales. A su vez, pueden, según sea el caso específico, estar acompañadas de obras de ingeniería hidráulica complementarias como represas, reservorios, galerías filtrantes, posas de disipación, canales de drenaje etc., destinadas a controlar el manejo del agua. Sus características varían según su ubicación agroecológica y su vocación productiva, y/o su época de construcción. Están concebidos 
para optimizar el control y el manejo del agua, aumentar la fertilidad y humedad de los suelos, evitar la erosión de los mismos, y, producir mejoras en el control del microclima. Constituyen efectivamente un capital físico y un patrimonio o infraestructura privada, comunal y pública.

\section{Estados imperiales, producción agrícola y segu- ridad alimentaria en los andes centrales}

La cantidad de fuerza de trabajo invertida para la construcción de los andenes a gran escala que alcanza a veces la artificialización o modelización del paisaje a nivel de valles completos con la finalidad de obtener excedentes productivos, tiene implicancias de carácter social, económico, político e ideológico. Presuponen una planificación previa de la construcción a gran escala con conocimientos técnicos de gran precisión, y, la posibilidad de manejar y trasladar una enorme cantidad de personas, mantenerlas y dirigirlas de manera centralizada durante los trabajos que se llevan a cabo para la construcción. Por el contrario, el mantenimiento y la producción anual en los andenes como el barbecho y siembra de las tierras, los cuidados y cosecha de los frutos, así como el eventual tratamiento, almacenamiento y traslado de los mismos, se pueden realizar sin necesidad de mayor cantidad de mano de obra que la que se puede controlar y convocar en un sólo valle. Por ello, entendemos que su construcción bajo un proyecto integral de manejo de cuenca, fue fruto de una organización política centralizada de nivel estatal. Su aprovechamiento en cambio sigue realizándose hoy en día como pudo ser durante los períodos hasta ahora llamados Intermedios en la arqueología peruana. Su utilización en dichas etapas históricas pudo ser parcial o total, y eventualmente pudieron haber sido abandonados por factores sociales o climáticos.

Como bien han enfatizado ciertos autores, la principal de esas carencias ha sido y sigue siendo la falta de agua para el riego y ésa debió ser la contradicción principal de los agricultores andinos en estas regiones. La resolución de esta contradicción fue la artificialización del medio físico a través de la construcción de andenes. Las sociedades agrícolas andinas hicieron frente a un medio sumamente duro, cuya principal dificultad fue reducir las posibilidades de perder las cosechas debido a los múltiples factores que inciden en su producción como las irregularidades de los ciclos climáticos, es decir, hacer frente y reducir el riesgo agrícola mediante la irrigación para alargar la temporada de crecimiento de los cultivos y estabilizar la producción (Masson 1986; Earls 1985; Treacy 1984; Morlon 1992).

Se considera tradicionalmente que la planificación y construcción de obras de irrigación y la organización de la utilización del agua requería la necesaria existencia del Estado. A pesar que en casos con condiciones particulares, estas tareas puedan llevarse a cabo por pequeños grupos organizados informalmente, la gestión centralizada del trabajo los hace más eficaces y potencia la proyección de las construcciones hidráulicas y su infraestructura anexa a gran escala. Por lo general, las personas que gestionan los recursos hidráulicos obtienen poder sobre los demás campesinos, factor que estaría en la base de un gobierno único centralizado que Wittfogel llama despotismo oriental y que correspondería también a las sociedades de los Andes centrales (Wittfogel 1957; Mitchell 1985; Redman 1990).

En el caso del valle del Colca la hipótesis de trabajo de Treacy es que la construcción del de los andenes se realizó en reemplazo de las terrazas de secano pre-existentes (Treacy 1984). Es interesante evaluar esta proposición: el problema principal para desarrollar la agricultura es la falta de agua y la falta de terrenos planos para cultivar en las faldas de los cerros. Si seguimos el desarrollo de esta proposición se incluye también el grave problema de las difíciles y fluctuantes condiciones climatológicas, obstáculo para 
asegurar la producción permanente de excedentes. Estos problemas habrían sido solucionados cambiando la agricultura en terrazas de secano por la agricultura en sistemas de andenes.

El área cultivada con andenes es a veces menor y en muchos casos inferior a la mitad del total cultivado anteriormente por secano, pero la productividad es mucho mayor, lo que permite obtener el mismo o mayor volumen de productos agrícolas y también una mejora en la calidad de los mismos, debido al control ejercido sobre los medios técnicos de la producción (Treacy 1984: 239-242).

En este punto la hipótesis es congruente con nuestra propuesta conceptual de separación de definiciones entre andén y terraza. Desarrollando una explicación teórica en términos marxistas nos encontramos frente a un caso de aumento de la productividad a través de la mejora de los medios de producción -una mejora de las condiciones técnicas del trabajo-, es decir de la generación de lo que Marx (1975) denominó un caso de plusvalía relativa (Lull y Risch 1995).

La propuesta de historiadores y arqueólogos basada en documentos históricos como Los Comentarios Reales de Garcilaso (1604), según la cual todas las modificaciones importantes del paisaje en tiempos anteriores a la conquista española fueron realizadas por los Incas ha sido descartada por los trabajos arqueológicos llevados a cabo en los últimos 30 años. Estas investigaciones han sido particularmente importantes en lo que a los sistemas de andenes se refiere en la zona sur del país, específicamente en la zona del valle sagrado de los Incas, en Cusco, donde trabajó la ONGD Cusichaca Trust dirigida por A. Kendall (1992, 1994, 1997).

Sin embargo, la posibilidad de la existencia del Estado obteniendo beneficios del cultivo del maíz desde época Huari ha sido planteada por los estudios de L. Valdez (2008) y Schreiber (1992, 1993, 2005). Se plantea que las tierras andenadas, es decir, las intencionalmente preparadas y mejoradas para la producción de maíz, eran aquellas que eran propiedad del Estado, sea las que pertenecían al Curaca local, al gobernante imperial impuesto o al culto religioso, ya sea en tiempos Huari o Incas.

Por otro lado, hay quienes insisten en la naturaleza no excedentaria de las economías agrícolas de zonas de montaña que sólo hubieran servido para el autoabastecimiento (Treacy 1984: 242; Morlon 1992). Si así fuera, tendríamos que responder a la pregunta de qué tipo de productos se estaban almacenando en la gran cantidad de colcas locales, provinciales y regionales de acuerdo a la jerarquía propuesta por la investigación de Morris (1985). Dichas colcas y depósitos que pueden hallarse en gran parte de los Andes centrales como un patrón generalizado datan por lo menos del Horizonte Medio. Más tardíamente estaban asegurando el abastecimiento de los tambos y las posibilidades del Estado Inca para llevar a cabo intercambios regionales de productos en la lógica de reciprocidad y redistribución propias del imperio (Murra, 1975, 1983).

Lo que queda pendiente de respuesta son preguntas básicas en la investigación: ¿qué tipo de cultivos existieron antes del maíz en esas terrazas de secano? Debieron ser de una enorme importancia para las sociedades andinas anteriores a los Huaris para justificar la inversión de mano de obra. Es probable que se tratara de cultivos de variedades de tubérculos andinos como la papa, el olluco, la mashwa o la oca asociados con Tarwi, u otros cereales andinos como la quinua y la Cañihua que en ciertas condiciones productivas aseguraran excedentes productivos. ¿De qué tiempo datan exactamente? Lamentablemente, ninguna excavación arqueológica seria se ha realizado al respecto y carecemos de información fiable sobre el particular. De allí que se justifique plenamente intentar llevar adelante un estudio que cruce variables provenientes de la agronomía, estudios paleoclimáticos y la ar- 
queología que nos permita afinar la cronología de antiguas terrazas y/o sistemas de andenes. $\mathrm{Ne}$ cesitamos que dicha investigación dé respuesta a aspectos muy concretos acerca de la producción y la productividad agrícola en las más antiguas terrazas existentes. Y finalmente, la más importante de las preguntas: ¿Qué tipo de sociedad y bajo qué relaciones sociales de producción hicieron posible la construcción de dichas terrazas y/ o andenes? Aquí también existe un debate interesante ya que los estudios llevados a cabo sobre sistemas de andenes enfocan mayormente el aspecto tecnológico y su evolución temporal pero pocos realizan estudios integrales que permitan una caracterización socio-política y el carácter de las formas de explotación de las sociedades que los produjeron.

Este aspecto, el de llegar a establecer el carácter de la organización socio-política de las sociedades andinas así como el de desocultar el carácter de las relaciones sociales de explotación en cada momento de su existencia, es una de las tareas más importantes de la arqueología como ciencia social. Además de una tecnología adecuada y una población numerosa se requiere una organización tal, que permita el mantenimiento de la mano de obra. El desplazamiento de contingentes de trabajadores desde otras provincias como el caso de los mitimaes descritos por las crónicas del siglo XVI en tiempos de los Incas, permitió llevar a cabo estas obras en un corto lapso no mayor a cinco décadas para cada valle intervenido. Los mecanismos de reciprocidad que establecieron generaron obligaciones mutuas. En ellas se esconden el carácter de explotación de la fuerza de trabajo y pueden crear la imagen de un Estado paternalista y socializante, y, de relaciones sociales igualitarias. Las relaciones sociales de producción que se establecen entre los campesinos que cultivan en los campos de andenes y quienes controlan su fuerza de trabajo y la propiedad de los medios de producción, son relaciones de explotación en una sociedad autocrática y marcado carácter clasista. Los Incas lejos de ser pioneros en estas formas despóticas de organización político-económica, son la manifestación tardía de lo que ya sucedía en los Andes desde el periodo Inicial hasta manifestaciones tardías como el imperio Huari.

Nuestro planteamiento, tal como ha quedado expuesto líneas atrás, es que fueron los Huari y no los Incas o algún Estado Regional Tardío, los que desarrollaron los andenes en el ámbito central andino a gran escala. La construcción de andenes, como llega a plantear Treacy (1984), no requiere de siglos de tiempo, sino una masa crítica de trabajadores.

Las grandes obras de infraestructura agrícola, que aún hoy, se hallan en funcionamiento, sólo pueden ser el resultado acumulado de una gran cantidad de fuerza de trabajo organizada de forma corporativa bajo el control centralizado de una entidad de carácter estatal, como lo fueron en su tiempo el imperio Huari, algunos Estados Regionales o el Imperio Inca para el caso de los Andes centrales. Al fundarse las reducciones en el siglo XVI, las tierras de cultivo quedaban muchas veces lejanas de los nuevos pueblos. La enorme disminución de la población hizo innecesaria la labor en los terrenos más alejados de cultivo que quedaron muy lejanos de los núcleos de población y así se abandonaron. Las causas del abandono de los andenes son comunes en la mayor parte de los Andes centrales. Denevan (1987) planteaba factores de carácter ambiental como un cambio climático brusco que produjo una mayor sequedad en las condiciones medioambientales y/o movimientos tectónicos que hubiesen generado problemas con las fuentes de abastecimiento de agua. También hacía alusión a factores histórico-sociales planteando que el colapso agrario y la disminución demográfica se habían presentado juntos y que era difícil definir la causa y el efecto entre estos dos factores (Denevan 1987:256). La debacle de la producción agrícola es producto de la desestructuración de 
la formación económico social ocurrida en los pueblos andinos con la imposición de la estructura colonial y de los cambios en las prácticas sociales y formas de producción que el nuevo orden impuso (Kendall 1992).

Datar los sistemas de andenes resulta una tarea complicada en la que se requiere una metodología muy compleja ${ }^{10}$. Entre otras cosas, existe escasa fragmentería de cerámica en los rellenos de los andenes y su ubicación estratigráfica no es confiable debido a las constantes alteraciones producto de la labranza y otras labores agrícolas en ellos realizados, así como los trabajos de reconstrucciones de que han sido objeto a lo largo de los siglos. En el caso del sistema de andenes de Andamarca, estos fueron construidos durante la época 2 del Horizonte Medio con la incursión de los Huari a la región (Schreiber 1987:270). Es posible que Canichi haya sido el asentamiento principal del sistema administrativo estatal para el valle del río Negromayo en tiempos Huari, época durante la cual las zonas agrícolas se ampliaron para garantizar una mayor producción de maíz y de otros productos agrícolas. Las investigaciones de Meddens (1981, 1984, 1990, 1991) en el valle de Chicha-Soras y las realizadas en el valle del Mantaro por Bonavía (1970) y por el Proyecto Alto Mantaro (Hastorf 1990; Parsons et al. 1997) sugieren que esta intensificación se debió principalmente a un aumento de las temperaturas, que a diferencia del período anterior, optimizó las condiciones para una mayor explotación de la tierra, construyendo un gran sistema de andenes el cual fue alimentado por el agua que discurría de los nevados por intermedio del deshielo de los glaciares (Branch et al. 2008:7).

La rehabilitación de sistemas andenes para la seguridad alimentaria de las poblaciones en los Andes centrales

Las comunidades campesinas del área andina central cuentan con un patrimonio productivo que se haya en estado de abandono: los sistemas de andenes o terrazas irrigadas de épocas prehispánicas ubicados en las zonas de laderas de

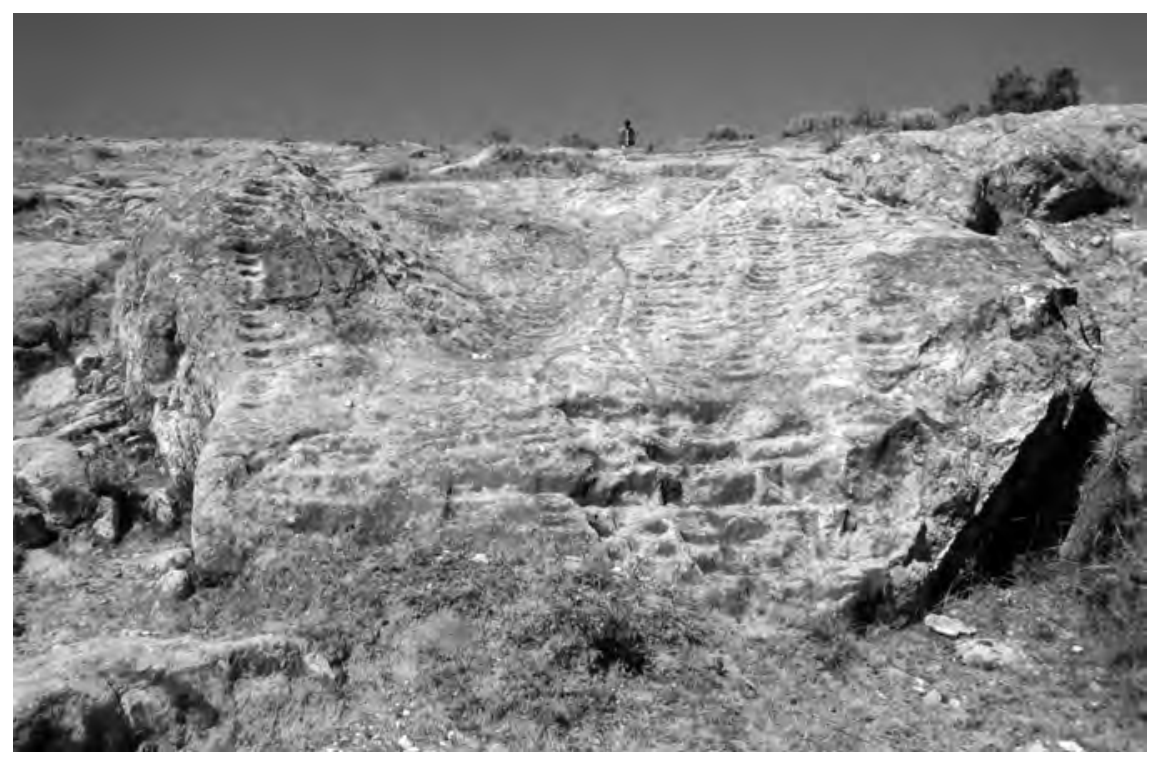

Foto 16. Vista en detalle de una maqueta de andenes ubicada durante las prospecciones en la margen izquierda del río Negromayo.

10 El desarrollo de esta metodología está inserta en el trabajo de tesis doctoral que el autor viene desarrollando. 
montañas (aproximadamente un millón de ha para el Perú $-75 \%$ se haya abandonada o con uso esporádico-) (Masson 1986, 1987). Debido a las condiciones geográficas de la región, las terrazas irrigadas han sido la forma histórica de aprovechamiento de las laderas de montaña para la producción agrícola complementadas por las actividades ganaderas.

A pesar de los múltiples pisos ecológicos que contienen los territorios de dichas comunidades y de la variedad de productos alimenticios nativos y/o complementarios que se cultivaron y que se podrían producir hoy, a bajo costo, miles de ha. de andenes se encuentran sin uso productivo; los índices de pobreza general y los de mal nutrición infantil en las poblaciones de montaña son alarmantemente elevados incluso en las serranías del departamento de Lima (60\% de la población escolar en Yauyos) mientras cada año que pasa incrementamos la importación de alimentos.
Factores agro-ecológicos y socio-económicos han contribuido a la ausencia de mantenimiento o abandono: cambio climático; migración de la población joven forzada a realizar trabajos de corta duración en las ciudades costeñas o en los campos cocaleros de la ceja de selva (Brougère 1992); baja competitividad de los productos determinada por su ubicación geográfica y los costos de transporte; ausencia de créditos y estrategias de mercado; falta de una política estatal coherente a largo plazo para el desarrollo agrario, y, baja cooperación para mantener de forma común los propios recursos naturales.

Un ejemplo que documenta las dificultades de las comunidades campesinas para el mantenimiento de los andenes y su productividad así como las prácticas agrícolas y de riego actuales en Andamarca fue documentado por el antropólogo Juan Ossio (1992) desde el punto de vista etnográfico y antropológico, quien describió muchas costumbres y prácticas agrícolas de los

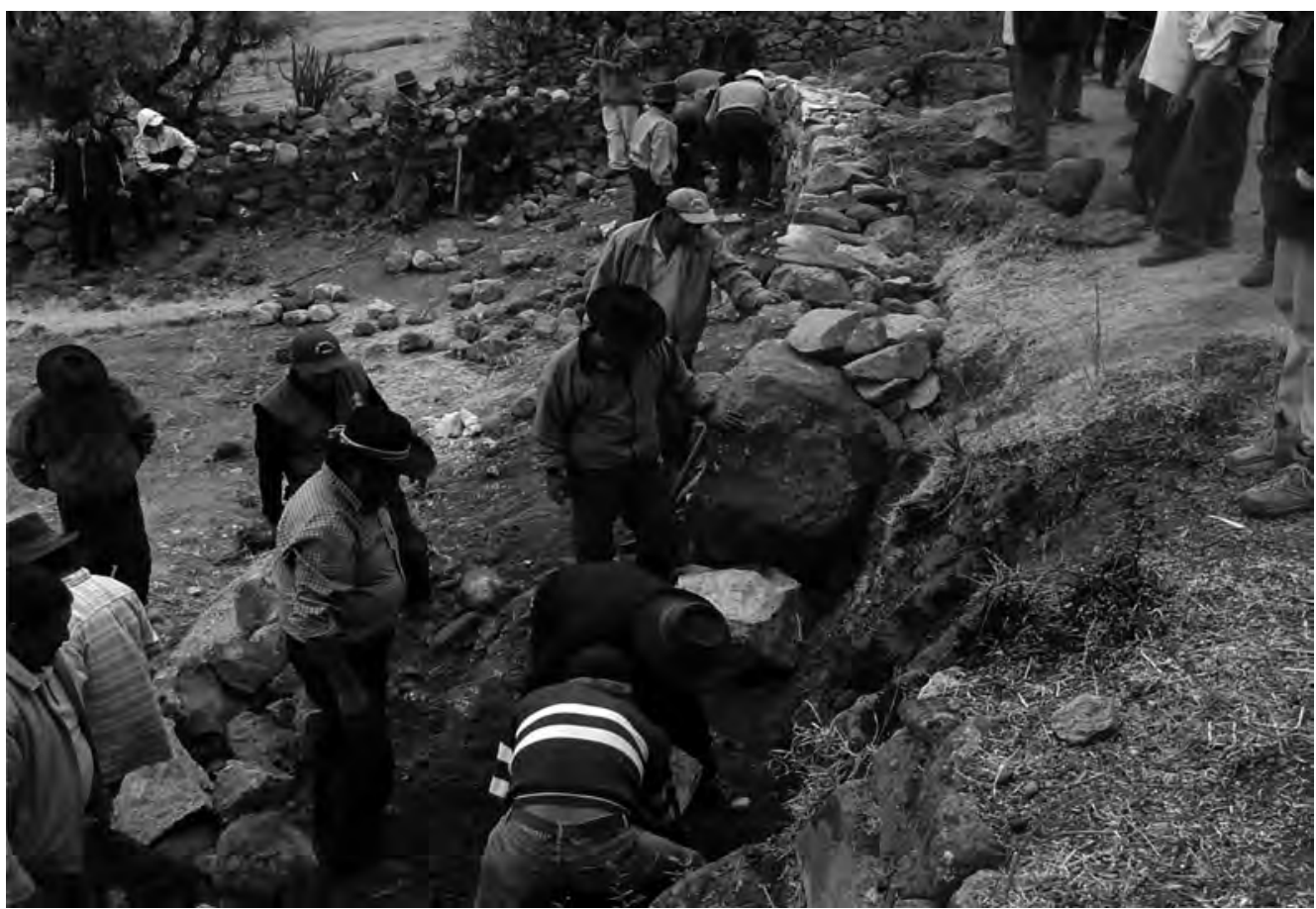

Foto 17. Concurso de rehabilitación de andenes en el pueblo de Cabana Sur (año 2005). 
vigentes considerando que la siembra del maíz es hoy una actividad familiar y no colectiva comunal. Sin embargo, no estamos seguros que esta fuera la situación en tiempos de los Huari o Incas, y nos inclinamos más bien, basados en los criterios ya mencionados líneas atrás, a pensar en faenas agrícolas como tareas colectivas para tiempos pre-hispánicos.

Actualmente, se nota ciertos cambios en sus tradiciones que van en detrimento del óptimo mantenimiento y tratamiento de los andenes y de los sistemas de riego. Por ejemplo, la técnica de usar grava y cascajo para el buen drenaje detrás de los muros de contención de los andenes no se sigue utilizando.

Por ello, es interesante investigar los muros y las partes prehispánicas no deterioradas así como los intervenidos por generaciones de agricultores recientemente para comparar sus resultados y conseguir mejorar y estandarizar el nivel de intervención optimizando las reconstrucciones para un óptimo manejo del agua y la conservación de los muros de los andenes.

El riego por inundación muchas veces sin control adecuado termina por hacer colapsar los muros de los andenes que son repuestos sin seguir las antiguas técnicas por lo que se realizan permanentes refacciones y se ocasiona la pérdida de suelos agrícolas.

Si bien existen estudios generales sobre las condiciones socio-económicas existentes en el presente en relación con las distintas vías posibles para su recuperación para la producción agrícola, esos diagnósticos no se ha traducido en estudios específicos para implementar un proyecto piloto que considere diferentes vías de valorización alternativas que pudieran tener los sistemas de terrazas irrigadas (patrimonial, ecológica, turística o paisajística).

Desde el campo de las ciencias económicas, tres posibles vías de recuperación de terrazas irrigadas han sido planteadas por Gonzales de Olarte y Trivelli (1999):
1. Desde el punto de vista mercantil la recuperación de los sistemas de terrazas irrigadas depende de que el agua y la tierra devengan capitales naturales o sus inversiones sean valorizados en el mercado. Los factores macro-económicos, políticos, sociales, culturales, institucionales y financieros han sido desarrollados por dichos autores.

2. Desde el punto de vista campesino, de ser posible su recuperación y puesta en uso social a través de la producción de cultivos nativos, se podría abastecer los mercados locales, allanar el camino hacia la autosuficiencia alimentaria y mejorar las condiciones de vida de las actuales poblaciones andinas. En ese sentido, la rehabilitación y el mejoramiento de los sistemas de terrazas irrigadas usando medios tradicionales y trabajo humano ha sido llevada a cabo y demostrada eficazmente a pequeña escala en varios proyectos ejecutados a nivel local (Kendall 1991; Ramos 1986; Masson 1986; Mejía 1992).

3. Desde el punto de vista de una política social del Estado, donde el mercado determine que la rehabilitación no es posible, la recuperación de los sistemas de terrazas irrigadas podría ser tomada para la subsistencia de los campesinos para la seguridad alimenticia o como resultado de políticas de estatales que posibiliten mejorar los servicios medioambientales, incluidos el turismo científico, ecológico y cultural.

Estas posibles vías de valorización de los sistemas de terrazas irrigadas (denominados andenes en el Perú) deben ser exploradas con mayor detalle, pero, a priori, no tendrían porque ser excluyentes entre sí. El estudio de todas las condiciones y alternativas citadas anteriormente resulta indispensable para producir líneas guías que sustenten la necesidad de rehabilitar y mejorar dicho patrimonio, y, que justifique la implementación de una política de estado en el Perú y los otros países andinos. 


\section{CONCLUSIONES}

1. Las excavaciones en los sectores de Chimpa y Huaylla evidencian que para la construcción de los andenes, se excavó la tierra cortando el suelo natural de la ladera en forma de gradas para preparar el terreno para la edificación de los muros de contención y para el acondicionamiento interno de la estructura en capas de suelos diferenciadas entre sí previamente preparadas. Nuestra hipótesis principal es que la construcción de andenes a nivel de todo un valle o sectores del mismo, sólo pueden responder a una planificación previa de una sociedad con poder centralizado capaz de planificar las obras a realizarse, y, movilizar y mantener ejércitos de trabajadores. Queda claro que la construcción de todo un sistema de andenes sólo fue posible bajo el manejo imperial primero de los Huari, y, en segundo término, los Incas. El aprovechamiento y mantenimiento pudo proseguir durante el Intermedio Tardío (con pequeñas ampliaciones para habilitar otros sub-sectores), o durante la época colonial (con un brusco descenso en el área productiva debido a la baja demográfica provocada por la llegada de los españoles) descuidando progresivamente su mantenimiento hasta su colapso y abandono parcial o total.

2. Sólo un conocimiento cabal y sistemático de la naturaleza de cada sub-sector de andenes (factores agua, suelo, y clima) permitió construir andenes irrigados, sabiendo previamente que cultivo se iba a sembrar, cambiando la combinación de los suelos y de las capas al interior del andén en función de: a) la posibilidad de conducir agua hacia los andenes; b) la vocación productiva de cada andén; c) la ubicación agro-ecológica de cada uno; d) las condiciones climáticas previsibles para los diferentes años de producción a través de calendarios agrícolas muy exactos, y, e) el dominio de ciertas prácticas agrícolas asociadas al cultivo de algunos cultívenos como la de cultivos asociados con el maíz (maíz/frejol en lugares inferiores a 3,000 m. de altitud y maíz /habas ó maíz/tarwi para lugares que pudieran alcanzar los $3,800 \mathrm{~m}$. de altitud, entre muchas otros ejemplos) u otros cultivos.

3. En el sector de andenes de Huaylla, deslizamientos de suelos semejantes a "huaycos" ocasionaron la destrucción de los muros de las estructuras y las terrazas de ocupación doméstica que existieron previamente a la construcción de andenes de parte de los Incas. Es necesario investigar, estos eventos naturales como causa probable de la destrucción de andenes pre-Incas en el ámbito de estudio del proyecto con futuras excavaciones. La posibilidad de que los poblados $o$ aldeas precedentes fueran expresamente destruidos por los Incas y reemplazados por andenes en las laderas de las montañas, como estrategia ideológica de ocupación, modificando el paisaje como muestra del poder imperial, sacando provecho al mismo tiempo de los productos de una mayor superficie cultivable para el maíz debe ser tomada en cuenta, posibilidad que ya ha sido tomada cierto sentido por K. Schreiber (2005).

4. En general, es muy difícil la identificación temporal de la construcción del andén (ubicación cronológica-corológica) tan sólo utilizando su aspecto externo (aparejo o técnica constructiva del muro de contención) como elemento diagnóstico. Los muros de contención de los andenes muchas veces engañan por su buen mantenimiento. La prospección nos ha permitido ver los diferentes momentos de intervención sufridos por los andenes a lo largo del tiempo. Sólo investigando la composición interna de las capas del andén a través de excavaciones es posible lograr su 
identificación cronológica precisa y/o identificar su vocación productiva.

5. En el sector de Tucuta ha sido interesante la identificación de una serie de andenes más tempranos que fueron enterrados y reemplazados por los actuales. Estos últimos también han sido intervenidos en tiempos recientes para su mantenimiento. Su posible asociación Rucana en un momento de cambios climáticos favorables para la ampliación de la superficie agrícola en piso ecológico Suni, nos situaría cronológicamente en los 1,300 d.C., lo que coincide con los cambios climáticos documentados para esa época, los cuales dieron lugar a la elevación de temperaturas y a mayores precipitaciones decalando los pisos ecológicos y sus características climáticas hacia arriba, apoyan esta hipótesis.

6. Los andenes se ubican en numerosas ocasiones sobre antiguos poblados más tempranos. Su remodelación formando sistemas de andenes en tiempos Incas o Huari, corresponden a momentos importantes de construcción y/o recuperación de la infraestructura agrícola. Mientras tanto, el abandono de poblados y a veces de sectores de andenes parece estar relacionado a causas asociadas a fenómenos naturales como huaycos o deslizamientos o sequías intensas.

7. En Andamarca, se han identificado los siguientes tipos de andenes de acuerdo a la tipología presentada por A. Kendall (2005): se tienen identificados andenes del tipo $1 \mathrm{Ay}$ 2B ambos pueden ser construidos siguiendo la pendiente natural del cerro o excavando éste a manera de corte y grada. En muchos andenes se observan diferentes etapas de intervención posteriores a la construcción inicial del andén original. Estas remodelaciones, reconstrucciones o recuperación de ciertos sectores o muros de andenes son posibles de diferenciarse cuando menos en dos grupos: a) reconstrucciones o intervenciones recientes que son todas aquellas realizadas en los últimos 50 años de las cuales se puede o no obtener información oral de parte de los comuneros; b) reconstrucciones o remodelaciones anteriores a 50 años ubicadas entre los periodos colonial y republicano, en donde un posible elemento identificador puede ser la presencia de un mayor número de líquenes más antiguos en las rocas, y; c) andenes inicialmente Huari, remodelados por los Incas.

8. Se viene corroborando que la construcción de los sistemas de andenes a nivel del valle del río Negromayo fue obra del imperio Huari. Sin embargo, la época de mayor intervención en la modificación del paisaje y la remodelación y la ampliación de espacios para la producción de maíz son obra de los Incas. Esto se debe a la necesidad estatal de producir más maíz en un contexto integral de mejoras importantes en el clima, que decalaron los pisos ecológicos hacia la parte alta. Esto quiere decir, que las características climáticas del piso Quechua llegaron por los menos a los $3,800 \mathrm{~m}$. permitiendo el cultivo del maíz a esa altitud.

9. La rehabilitación de andenes requiere de estudios multidisciplinarios y una clara política de desarrollo a largo plazo en el país conociendo el modelo económico y social en el cual se imbricarían. Salvo en casos muy particulares, un absurdo, pensar en recuperar andenes dentro del marco de la política neoliberal que vivimos. Sin embargo, un giro en la situación climática mundial que ya apreciamos y un considerable aumento demográfico de las poblaciones en los Andes centrales pueden hacer reconsiderar esta opción. Por ello, resulta de vital importancia, el estudio de los aspectos técnicos y sociales vinculados a su óptimo funcionamiento en tiempos pre-hispánicos. 


\section{Agradecimientos}

Quiero expresar mi gratitud a la población del distrito de Andamarca, la cual viene colaborando entusiastamente con los trabajos arqueológicos y acogiendo los resultados que están arrojando nuestras investigaciones sobre los andenes prehispánicos para retomar técnicas olvidadas que son sugeridas para la optimización de la agricultura en andenes.

Agradezco de manera especial a la Dra. Ann Kendall por brindarme la oportunidad de realizar conjuntamente esta investigación. Un agradecimiento especial por el apoyo logístico y del personal a la ONG Cusichaca Trust.

Agradezco también las facilidades brindadas por el Director del Museo de Arqueología de la U.N.M.S.M., Lic. Carlos del Aguila, por brindarnos el acceso y las facilidades para analizar el material cerámico depositado en nuestro Museo universitario.

Finalmente, quiero mencionar que gracias al entusiasmo y dedicación de los estudiantes de arqueología de la U.N.M.S.M., Sonia Berrocal y Jorge Cámara, quienes preparan sus tesis de licenciatura sobre la producción alfafera y los patrones de asentamiento en la zona del valle bajo del río Negromayo, respectivamente, me motivó ha retomar la preparación de las publicaciones de los resultados de los trabajos de campo en los andenes de Andamarca. Hemos desarrollado una interesante dinámica de trabajo y hemos asumido el reto de seguir realizando investigaciones arqueológicas en este valle.

\section{Bibliografía}

Aguirre-Morales, M.

2005a Los andenes de la sub-cuenca del río Ayavirí - Yauyos. Seminario de Historia Rural Andina de la Universidad Nacional Mayor de San Marcos, Lima.

2005b La Arqueología Social en el Perú. BAR International Series 1396, Oxford.

2009 "Arqueologia y reivindicaciones poli- tico-sociales: intengrando colectivos para la defensa del patrimonio cultural y la seguridad alimentaria de los pueblos y comunidades de América Latina”. Ponencia presentada en el Simposio Arqueologia Social Latinoamericana "De la teoría a la praxis", y en el 53 ICA (México 2009).

Araujo, $\mathrm{H}$.

1986 "Hacia una política nacional de recuperación de andenes". En: Andenería, conservación de suelos y desarrollo rural en los Andes peruanos. J. Portocarrero Maisch (ed.); Ministerio de Agricultura -PRONAMACHS- Ministerio de Vivienda y Construcción -Programa de acondicionamiento territorial y vivienda rural- Naturaleza Ciencia y Tecnología Local - Fundación Friedrich Ebert. Lima, Pp. 13 - 29.

Branch, N., R. Kemp, B. Silva, F. Meddens, A. Williams, A. Kendall y C. Vivanco.

2007 "Testing the sustainability and sensitivity to climatic change of terrace agricultural systems in the Peruvian Andes: a pilot study". Journal of Archaeological Science 34(1), Pp.1-9.

Brougère, A. M.

1992 iY por qué no quedarse en Laraos? Migración y retorno en una comunidad altoandina. IFEA - INANDEP, LimaPerú.

Bonavia, D.

1970 "Investigaciones arqueológicas en el Mantaro Medio". En: Revista del Museo Nacional, Tomo XXXV, Pp. 211194.

1991 Perú, hombre e historia. De los orígenes al siglo XV. Ediciones EDUBANCO, Lima.

Bonavia, D. y R. Matos.

1990 "La recuperación de los terrenos agrícolas irealidad o utopía?". En: Revista Peruana de Ciencias Sociales, 2(2), Pp. $61-72$. 
M. Burga y C. de la Torre (eds.).

1987 Andenes y camellones en el Perú antiguo. Historia, presente y futuro. Ministerio de la Presidencia - Consejo Nacional de Ciencia y Tecnología (CONCYTEC). Lima.

Chepstow-Lusty, A.; D. K. Bennet,; V. R. Switsur, y A. Kendall

1986 "400 years of human impact and vegetation change in the Central Peruvian Andes. Parallel with events from the Maya record". Antiquity № 70, pp. 923-933.

Cieza de León, P. De.

[1550] Crónica del Perú. Segunda parte. Edición, prólogo y notas de Francesca Cantú. Fondo Editorial de la Pontificia Universidad Católica del Perú y Academia Nacional de la Historia, (1987), Lima.

\section{D'Altroy, T.}

1992 Provincial Power in the Inka Empire. Smithsonian Institution Press. Washington D.C.

Denevan, W. et al. (eds.).

1987 "Pre-hispanic agricultural fields in the andean region". En: Proceedings 45. Congreso Internacional de Americanistas 1985. BAR International Series 359. Bogotá, Colombia.

Dollfus, O.

1981 El reto del espacio andino. Instituto de Estudios Peruanos. Lima,

Donkin, R. A.

1979 Agricultural terracing in the new world. Viking Fund publications in Anthropology 65, Wenner-Gren foundation for anthropological research, inc.

Duviols, P.

1973 "Huari y Llacuaz: agricultores y pastores. Un dualismo prehispánico de oposición y complementariedad". En: Revista del Museo Nacional, Tomo XXXIX, Pp. 153-191.
Earls, J.

1989 Planificación agrícola andina. Bases para un manejo cibernético de sistemas de andenes. Centro de Investigación de la Universidad del Pacífico - Ediciones de la Corporación Financiera de Desarrollo (COFIDE). Lima.

Earls, J.; Grillo, E.; Araujo,; H y J. Van Kessel.

1990 Tecnología Andina: Una Introducción. La Paz.

Felipe-Morales, C.

1987 "La erosión de los andenes en zonas pobladas de altura". Pensamiento Iberoamericano 12, Madrid, pp. 97-108.

1993 "Relaciones agua/suelo bajo condiciones del agroecosistema andino". En: El agroecosistema andino: problemas, limitaciones perspectivas. Centro Internacional de la Papa (CIP), Lima, Pp. 139-153.

1994 "Pérdida de agua, suelo y nutrientes bajo diversos sistemas de cultivo y prácticas de conservación del suelo en zonas áridas, subhúmedas y muy húmedas en el Perú". En: Perú. El problema agrario en debate. SEPIA $V$, Dancourt, O.; E. Mayer y C. Monge (eds.). Seminario Permanente de Investigación Agraria. Universidad Nacional de San Agustín. Centro de Apoyo y Promoción del Desarrollo Agrario. Pp. 637-656

Fonseca, C. y E. Mayer

1988a Comunidad y producción en la agricultura andina. E. Mayer (Comp.), Asociación Peruana para el Fomento de las Ciencias Sociales (FOMCIENCIAS), Lima.

1988b "Sistemas agrarios en la cuenca del río Cañete". En: Comunidad y producción en la agricultura andina. E. Mayer (Comp.), Asociación Peruana para el Fomento de las Ciencias Sociales (FOMCIENCIAS), Lima. Pp. 1 - 38. 
1988c "Zonas de producción de la cuenca". En: Comunidad y producción en la agricultura andina. E. Mayer (Comp.), Asociación Peruana para el Fomento de las Ciencias Sociales (FOMCIENCIAS), Pp. 65-98, Lima.

Garcilaso de la Vega.

[1604] Comentarios reales de los Incas. Biblioteca de Autores Españoles, Vol. 133, 1960, Madrid.

Golte, J.

1980 La racionalidad de la organización andina. Instituto de Estudios Peruanos, Lima, Perú.

Gonzales-Carré, Enrique

1992 Los Señoríos Chankas. Instituto Andino de Estudios Arqueológicos - Universidad de San Cristóbal de Huamanga.

Gonzales de Olarte, E. y C. Trivelli

1999 Andenes y desarrollo sustentable. Instituto de Estudios Peruanos (IEP) Consorcio para el Desarrollo Sostenible en la Ecorregión Andina (CONDESAN). Lima.

Grillo, E.

1990a "Rescate y sistematización de tecnologías andinas". En: Tecnología Andina: Una Introducción. Earls, J.; Grillo, E.; Araujo,; H y J. Van Kessel, La Paz. Pp. 35-86.

1990b Población, agricultura y alimentación en el Perú. Cultura andina y salud de la naturaleza y de la sociedad. Proyecto Andino de Tecnologías Campesinas, (PRATEC), Lima.

Guamán Poma de Ayala, Felipe.

[1607?] El primer nueva corónica y buen gobierno, Murra, J. V. y R. Adorno (eds.), 3 tomos. Siglo XXI. (1983), México.

Heather, L. y A.M. Soldi

1985 La tecnología en el mundo andino. Runakunap Kawsayminkupaq Rurasqancunaqa. Universidad Nacional Autónoma de México. Imprenta Universitaria, México D.F.
Hastorf, C.

1990 "The effect of the Inka State on Sausa agricultural production and crop consumption”. American Antiquity 55(2). Pp. 262 - 290.

Hastorf, C. y Johannessen, S.

1993 "Pre-Hispanic political change and the role of Maize in the central Andes of Peru". American Anthropologist 95(1). Pp. 115 - 138.

Instituto Geográfico Militar (I.G.M.)

1980 Carta Geográfica Nacional (2142)

- Querobamba (29 - o) - Escala 1/100,000 - Lima,

Isbell, W. y G. F. McEwan, (eds.)

1991 Huari administrative structure. Prehistoric monumental architecture and state governement. Dumbarton Oaks, Washington D.C.

Keeley, H.M. and F.M.Meddens

1993 "Prehispanic Agricultural Terraces in the Chicha Soras Valley, Peru". En: Institute Archaeological Bulletin, Number 29, Institute of Archaeology. Gordon Square, London, pp.121-138.

Kendall, A.

1976 "Descripción e inventario de las formas arquitectónicas incas”. En: Revista del Museo Nacional, Tomo XLII, Pp. 13-96.

1984 "Archaeological Investigations of the late Intermediate Period and Late Horizon Period at Cusichaca, Perú". En: Current Archaeological Projects in the central Andes, British International Series 210, Oxford.

1992a Los patrones de asentamiento y desarrollo rural prehispánico entre Ollantaytambo y Machu Picchu. Proyecto Cusichaca - Universidad Nacional San Antonio Abad del Cusco. Editorial Universitaria de la UNSAAC, Cusco, Perú.

1992b Infraestructura hidráulicapre-hispánica: presente y futuro. Tarea, Asociación Gráfica Educativa. Lima. 
1992c “Arqueología, tecnología prehispánica y desarrollo rural". En: Infraestructura Agrícola e Hidráulica Prehispánica. Presente y Futuro. Kendall, A. (ed.), pp. 11-19, Cusco.

1994 Proyecto Arqueológico Cusichaca, Cusco. Investigaciones arqueológicas y rehabilitación agrícola. Tomo I. Cusichaca Trust - Southern Perú. Lima, Perú.

2005 Restauración agrícola en los Andes: Recuperación de los sistemas tradicionales de riego y andenes agrícolas. The Cusichaca Trust. Ayacucho.

C. Llerena, M. Inbar y M. Benavides (eds.).

2004 Conservación y abandono de Andenes. En: Universidad Nacional Agraria La Molina - Universidad de Haifa, Israel. Lima.

Lull, V. y R. Roberto

1995 "El Estado Argárico". En: Verdolay № 7, Pp. 19-28. España.

Lumbreras, L.

1974 “Chankas y Pocras”. En: Las Fundaciones de Huamanga. Hacia una Prehistoria de Ayacucho. Club de Huamanga. Lima.

1996 "Memorial del patrimonio Agrario". En: Boletín del centro de ciencias del hombre. Universidad Estadual Nor Fluminense. Fundación Estadual Nor Fluminense. Río de Janeiro - Brasil.

2001 "El Imperio Wari”. En: Las formas históricas del Perú, № 8. Instituto Francés de Estudios Andinos - Lluvia Editores, Lima, Perú.

Marx, Karl

1867 El Capital. Volumen I. Siglo XXI, 1975, España.

Masson, L.

1986 "Experiencias en San Pedro de Casta". En: Andenes y camellones en el antiguo Perú. Javier Portocarrero Maish (ed.), Ministerio de Agricultura - PRONAMACHS - Ministerio de Vivienda y Construcción - Programa de acondi- cionamiento territorial y vivienda rural - Naturaleza, Ciencia y Tecnología Local - Fundación Friedrich Ebert. Lima, Pp. 25-29.

1987 "Rehabilitación de andenes en la comunidad de San Pedro de Casta". En: Andenes y camellones en el Perú antiguo. Historia, presente y futuro. M. Burga y C. de la Torre (eds.), Ministerio de la Presidencia - Consejo Nacional de Ciencia y Tecnología (CONCYTEC). Lima. Pp. 207 - 216.

Meddens, F.M.

1981 "Investigations in the Chicha Valley, Peru”. En: Institute of Archaeology Bulletin, $\mathrm{n}^{\circ} 18$, Gordon Square, London, Pp. 209-223.

1984 "Report on the Archaeology of the Chicha-Soras valley", Ponencia presentada al Congreso de Americanistas en Manchester, Inglaterra, 1982. En: Current Archaeological Projects in the Central Andes, British Archaeological Reports 210, A. Kendall (ed.), Pp.133151.

1991 "A Provincial Perspective of Huari Organisation viewed from the Chicha-Soras Valley". En: Huari Administrative Structure, Prehistorical Monumental Architecture and State Government, G McEwan and W.H. Isbell (eds.), Dumbarton Oaks, Washington D.C., Pp. 215 -231.

Mejía, A.

1992 Proyecto de rehabilitación de andenes de la microcuenca de Callumayo - Lari. Centro de Estudios y Promoción del Desarrollo Elaboración Técnica (DESCO) - Agencia Española de Cooperación Internacional (AECI), En: El valle del Colca. AECI - MITINCI - PROMPERU, Desarrollo y Comunicación (DESYCOM). Perú. 1 disco compacto. 
Mitchel, W.

1981 "La agricultura de riego en la sierra central de los Andes: implicaciones para el desarrollo del estado". En: La tecnología en el mundo andino. Runakunap Kawsayninkupaq Rurasqancunaqa. Universidad Nacional Autónoma de México, Imprenta Universitaria, México D.F.

Morlon, P. (cord. y ed.)

1992 Comprendre l'agriculture paysanne dans les Andes centrales. Pérou - Bolivie. Institut National de la Recherche Agronomique (INRA). Paris.

Morris, C.

1985 “Tecnología y organización Inca del almacenamiento de víveres en la Sierra”. En: La tecnología en el mundo andino. Runakunap Kawsayninkupaq Rurasqancunaqa. Universidad Nacional Autónoma de México, Imprenta Universitaria, México D.F.

Mujica, E. y L. Rueda (eds.)

1995 El desarrollo sostenible de montañas en América Latina. Consulta intergubernamental 1995. CONDESAN - CIP - FAO, Lima.

Mujica E. et al.

2004 "Bibliografía extensiva sobre andenes en los Andes centrales". Mujica, E.; Aguirre-Morales, M.; Inbar, M.; Riveros, L. y C. Llerena (Comps.); En: Conservación y abandono de Andenes. C. Llerena, M. Inbar y M. Benavides (eds.). Universidad Nacional Agraria La Molina - Universidad de Haifa, Israel. Lima.

Murra, J.

2004 El mundo Andino. Población, medio ambiente y economía. Instituto de Estudios Peruanos - Pontificia Universidad Católica del Perú. Lima.
2007 [1955] La Organización Económica del Estado Inca. Siglo XXI Editores. México D.F.

Ossio, J.

1987 "Las andenerías de la comunidad de Andamarca (Ayacucho, Perú)”. En: Seminario sobre Tecnologías Tradicionales. Primera Reunión de Manejo de Suelos y Agua en la Sociedad Andina (Cieneguilla). Asociación Peruana para el Fomento de las Ciencias Sociales (FOMCIENCIAS), Lima.

1992 Parentesco, reciprocidad y jerarquía en los Andes. Una aproximación a la organización social de la comunidad de Andamarca. Fondo Editorial de la Pontificia Universidad Católica del Perú. Lima.

Parsons, J.; Hastings, Ch. y R. Matos

1997 "Rebuilding the State in Highland Peru: Herder-cultivator interaction during the Late Intermediate Period in the Tarama-Chinchaycocha Region”. Latin American Antiquity, 8(4), Pp. 317-341.

Potocarrero, J. (ed.)

1986 Andenería, conservación de suelos y desarrollo rural en los Andes peruanos. Ministerio de Agricultura (PRONAMACHS) - Ministerio de Vivienda y Construcción - Programa de acondicionamiento territorial y vivienda rural - Naturaleza Ciencia y Tecnología Local - Fundación Friedrich Ebert.

Ramos, C.

1987 "Reconstrucción, refacción y manejo de andenes en Asillo (Puno). En: Andenes y camellones en el Perú antiguo. Historia, presente y futuro. M. Burga y C. de la Torre (eds.), Ministerio de la Presidencia - Consejo Nacional de Ciencia y Tecnología (CONCYTEC). Lima. Pp. 225 - 239. 
Redman, C.

1978 Los orígenes de la civilización. Desde los primeros agricultores hasta la sociedad urbana en el próximo oriente. Editorial Crítica, 1990, Barcelona.

Schreiber, K.

1987 "Conquest and consolidation: a comparison of the Wari and Inka occupations of a highland peruvian valley". American Antiquity, 52(2), Pp. 266 284.

1991a "The association between roads and politics: evidence for Wari roads in Peru". En: Ancient road networks and settlement hierarchies in the New World. Trombold, Ch., (ed.), Cambridge University, pp. 243-252.

1991b "Jincamocco: a Huari Administrative Center in the South Central Highland of Peru. En: Huari Administrative Structure: Prehistoric Monumental Architecture and State Government. W. Isbell y G. McEwan (eds.), Dumbarton Oaks, Washington D.C. pp. 199. 213.

1992 Wari Imperialism in Middle Horizon Peru. Anthropological Papers 87. University of Michigan.

1993 "The Inca occupation of the province of Andamarca, Lucanas, Peru". En: Provincial Inca: Archaeological and Ethnohistorical Assessment of the Impact of the Inca State. Malpass, M. (ed.), University of Iowa Press, Pp. 78-116.

2005 "Sacred landscapes and imperial ideologies: The Wari empire in Sondondo, Peru". En: Foundations and Relations of Power in the Prehispanic Andes. Vaughn, K., Ooburn, D., y C. Conlee. (eds.); Archaeological Papers of the American Anthropological Association 14. Pp. 131-150.
Treacy, J. M.

1994 Las chacras de Coporaque. Andenería y riego en el valle del Colca. María A. Benavides et al. (eds.); Instituto de Estudios Peruanos (IEP), Lima.

Usselmann, Pierre

1986 "Una cercamiento a las modificaciones del medio físico latinoamericano durante la colonización: consideraciones generales y algunos ejemplos en las montañas tropicales". En: Boletín del Instituto francés de estudios andinos, Tomo XVI. № 3-4, Lima.

Valdéz, L.

2008 "Maize beer production in Middle Horizon, Peru". En: Journal of Anthropological Research, Vol. 62. The University of New Mexico. Pp. 53 - 80.

Wittfogel, K.

1957 Oriental despotism. A Comprative studyt of total power. Yale University Press, New Haven. 